A STUDY OF WATER CIRCULATION IN MONTEREY HARBOR USING RHODAMINE B DYE

JOHN F. BREDENSTEN DAVID M. THOMAS 


\section{DUDLEY KNOX LIBRARY}

NAVAL POSTGRADUATE SCHOOL.

MONTEREY, CA 93943-5101 



A STUDY OF WATER CIRCULATION IN

MONTEREY HARBOR USING RHODAMINE B DYE

$* * * * *$

John F. Breidenstein

and

David M. Thomas 



\title{
A STUDY OF WATER CIRCULATION IN
}

MONTEREY HARBOR USING RHODAMINE B DYE

\author{
by \\ John F. Breidenstein \\ "I \\ Lieutenant, United States Navy \\ and \\ David M. Thomas \\ Lieutenant, United States Navy
}

Submitted in partial fulfillment of the requirements for the degree of

MASTER OF SCIENCE

United States Naval Postgraduate School

Monterey, California

1965 
F

$$
\begin{aligned}
& \text { NPE APAHIE } \\
& 196
\end{aligned}
$$

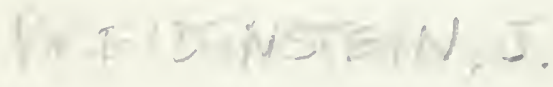


MONTEREY, CA 93943-5101

\section{A STUDY OF WATER CIRCULATION IN}

MONTEREY HARBOR USING RHODAMINE B DYE

by

John F。Breidenstein

and

David M. Thomas

This work is accepted as fulfilling

the thesis requirements for the degree of

MASTER OF SCIENCE

from the

Únited States Naval Postgraduate School 



\section{ABSTRACT}

Rhodamine B dye was used to determine water circulation in Monterey Harbor. Point and line dye sources were traced visually, photographically, and by use of a fluorometer. The spreading of dye boundaries and the concentrations observed are presented in a time series of synoptic charts for each of the four surveys conducted. From these measurements, mean flow rates and a dye diffusion rate were determined. Circulation was found to be dominated by tidal currents, but wind-driven currents were important in the outer harbor. In the outer harbor, the circulation proved to be counterclockwise during rising tide, and clockwise during the falling tide. Flow was minimal in the inner harbor, or marina. Limited data indicate that the subsurface circulation agreed with the surface circulation in most of the surveys . 

Section

$\underline{\text { Page }}$

Introduction

1

Procedures and Equipment

8

Results

Survey 1

23

Survey 2

27

Survey 3

31

Survey 4

32

Composite Circulation

61

Acknowledgments

65

Bibliography

66 



\section{LIST OF ILLUSTRATIONS}

Figure

Page

1. Monterey Bay, California 5

2. Monterey Harbor, California 6

3. ' Monterey Harbor Bottom Contours 7

4. Schematic Diagram of Equipment 10

5. Tidal Ranges During Surveys 18

6A-E. Dye Movement; Survey 1, February 6, 1965 35-39

7A-D. Dye Distribution; Survey 1, February 6, 1965 40-43

8A-C. Dye Movement; Survey 2, February 20, $1965 \quad 44-46$

9A-C. Dye Distribution; Survey 2, February 20, 1965 47-49

10. Dye Distribution; Survey 2, February 21, $1965 \quad 50$

11A-B . Dye Movement; Survey 3, March 19, $1965 \quad 51-58$

12A-B. Dye Distribution; Survey 3, March 19, 1965 58-54

13A-C. Dye Movement; Survey 4, March 26, $1965 \quad 55-57$

14A-C. Dye Distribution; Survey 4, March 26, $1965 \quad 58-60$

15. Current Flow During Rising Tide 63

16. Current Flow During Falling Tide 64 



\section{INTRODUCTION}

The principal purpose of the research described in this paper was to determine from field observations the surface and subsurface water circulation within Monterey Harbor. The circulation was presumed to be tidally induced; accordingly, surveys were scheduled in relation to

- the tides. The circulation was determined by using Rhodamine B, a bright-red fluorescent dye, which was traced visually, photographically, and with the use of a continuously recording fluorometer. The technique of tracing water movement using Rhodamine $B$ and a fluorometer has the advantage that dye concentrations well below the visual threshold can be measured. This makes it possible to trace the movement of a patch of dyed water for several days after the dye is released. The instrument used in this study, while not the most sensitive available, can detect concentrations of Rhodamine B as low as 0.05 parts per billion.

Four surveys of from one to three days duration were conducted during the months of February and March, 1965. These surveys were concentrated within the harbor and marina area, but whenever dyed water moved out of the harbor area, and sea conditions permitted, fluorometer readings and visual observations were extended into the open bay. The study involved the evaluation of both point-source and line-source dye injection patterns. In all cases, the dye was introduced into the water 

at one time and no continuing sources were utilized. Because time changes in a dye patch include the effects of advection and diffusion, the analysis of the survey data yielded some information on diffusion as well, which is included.

Monterey Harbor, where this study was conducted, is located in the extreme southern end of Monterey Bay, in the well-sheltered lee of the Monterey Peninsula (Figure 1). The harbor is enclosed by a rubble breakwater and also by a continuous solid bulkhead constructed along the landward half of Municipal Wharf No. 2 and a long the Marina Boundary Wall (Figures 2 and 3).

The harbor entrance is considered in this study to be marked by a line connecting the seaward end of the breakwater and the western end of the Marina Boundary Wall (Figure 3). The inner portibn of the harbor, enclosed by the solid bulkheads and located between the two wharves, is referred to as the marina.

The selection of Rhodamine B as a tracer dye was based on the results of studies made by Pritchard and Carpenter (1960) at the Chesapeake Bay Institute and by Feuerstein and Selleck (1963) at the University of California. The major reasons for its use were:

1. Rhodamine $B$ is harmless to human and marine life in concentrations at least as high as 100 milliliters per liter. 

2. Rhodamine B dissolves readily in sea water and remains in solution for relatively long periods of time.

3. Rhodamine B is available commercially (DuPont) and is inexpensive.

4. The color of Rhodamine B differs strikingly from the sea. This permits detailed visual observations and good color photography for several hours after the dye is introduced into the water.

5. Rhodamine B can be readily distinguished from naturally occurring fluorescent substances in sea water when using a fluorometer. The peak fluorescence of the dye occurs at a wave length of about 575 millimicrons, whereas most organic pigments occurring in the background fluoresce in the range from 650 to 700 millimicrons.

6. The photochemical decay rate of Rhodamine B in sunlight is negligible in comparison to the reduction in concentration which results from diffusion. This enables a study to be conducted for several days, until the dye is dispersed.

The only disadvantage involved with the use of Rhodamine B is that it is adsorbed onto organic and sediment particles. Feuerstein and Selleck (1963) found that dye adsorption is inversely proportional to 

chlorosity and that it amounts to only a small percent for normal salinity sea water. In view of this, and because the surveys were conducted during the winter months when the microorganism content of the water is characteristically at a minimum, adsorption was considered of secondary consequence in the semiquantitative surveys undertaken here. 



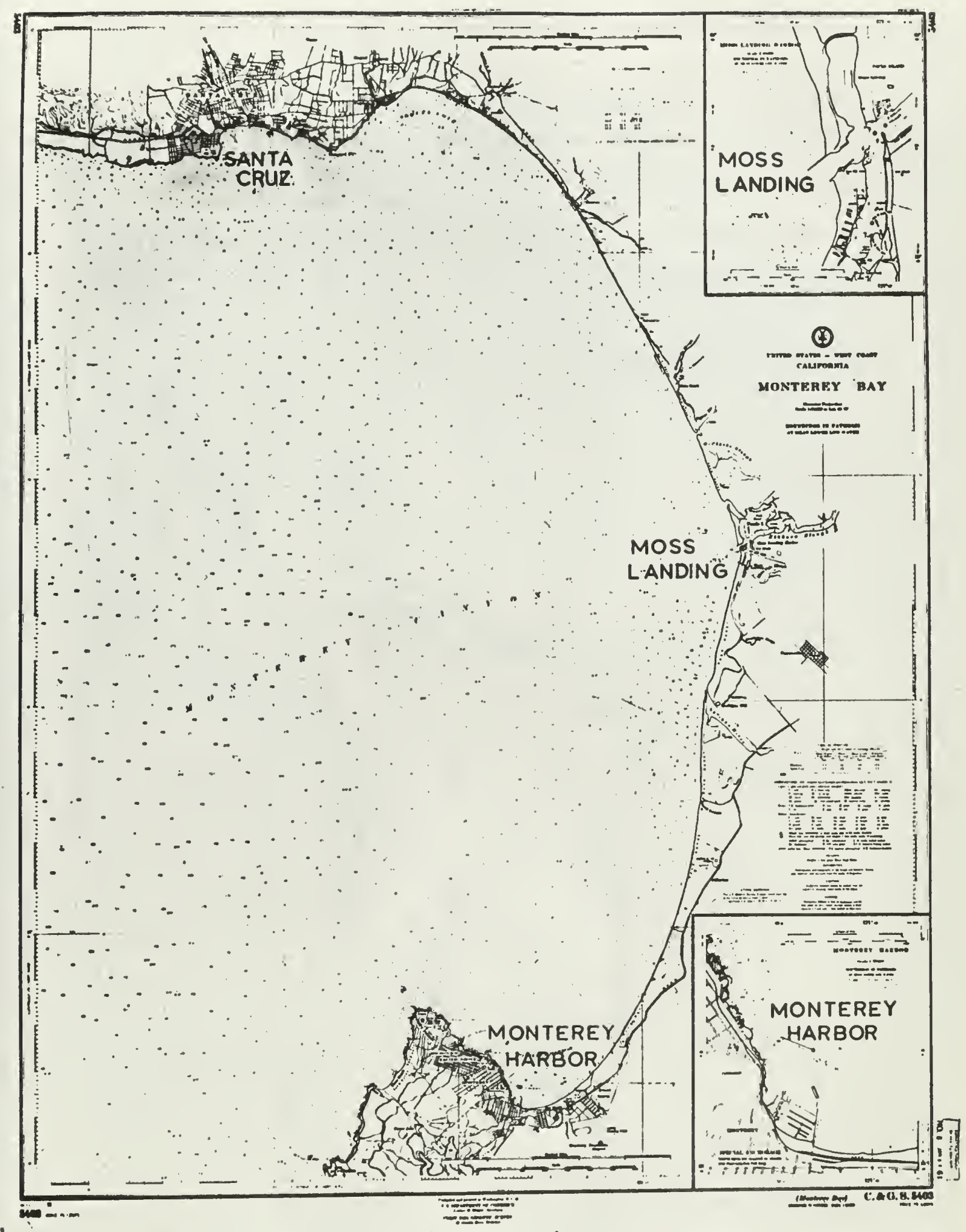

Figure 1 



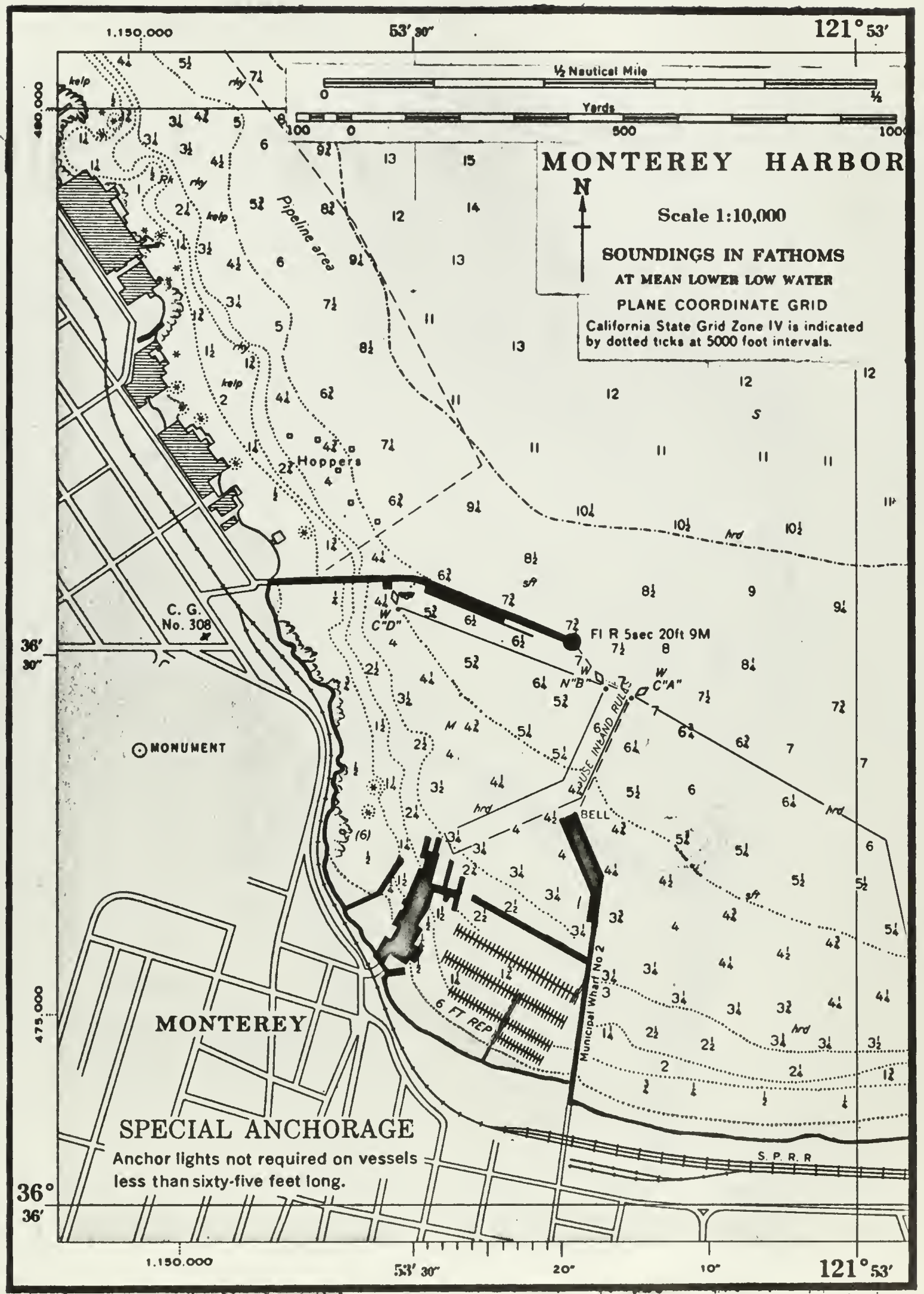

Figure 2 



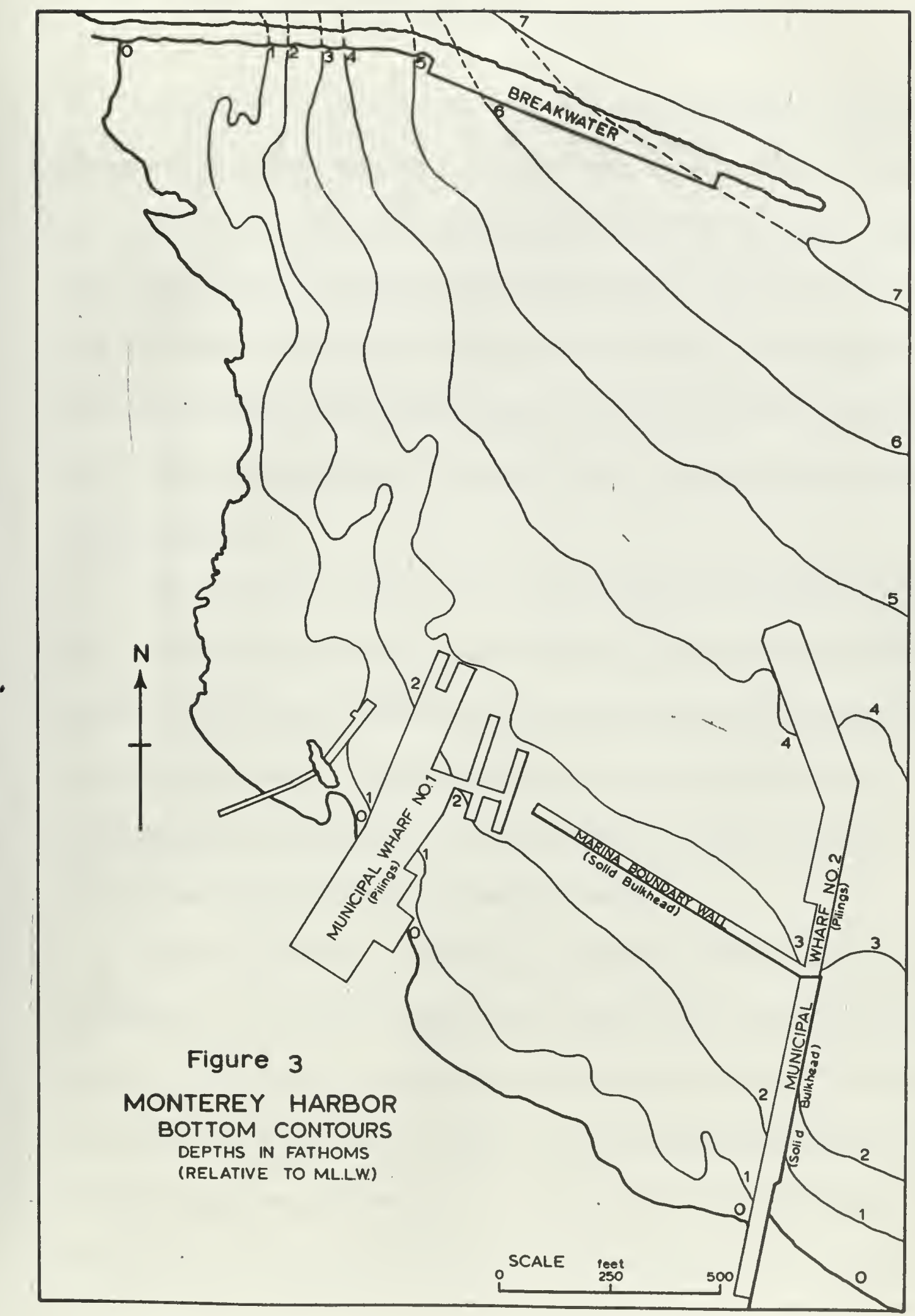





\section{PROCEDURES AND EQUIPMENT}

Tracing of the dye in the field was accomplished in three ways: the position of the boundary of the dye was visually observed from a boat at intervals throughout each of the four surveys; photographs and sketches were made from a helicopter in the early stages of two surveys when the dye was most visible from the air; and fluorometer measurements of the dye concentration were made by boat in the later stages of each survey when diffusion reduced the concentration to values low enough for reading by fluorometer.

The first three surveys were begun during the incoming or rising tide. The dye was placed in the water after sufficient time had elapsed following low tide to insure that the current flow was that associated with the rising tide. The fourth survey was conducted during the outgoing or falling tide. As before, the dye was not introduced until the currents associated with the falling tide were flowing.

During all surveys the dye was emplaced in the morning, and its movement was followed almost continuously for the remainder of the day, until sunset or weather conditions prevented further work. Readings were taken with the fluorometer to determine the distribution of the residual dye on the second day of Survey 1 and on the second and third days of Survey 2 . Because of the movement of the dye out of the harbor during Survey 3 and 

because of the small amounts of dye used in Survey 4, readings were not taken after the first day of these two surveys.

The method employed in tracing the dye visually from a boat was to follow the outline of the dye while sketching the visual boundary on a harbor chart. When the fluorometer was used, later on in the survey, the boat runs were designed to provide good coverage of the harbor. It normally took at least 30 to 40 minutes to cover the area of dyed water.

The fluorometer used was a Turner Model 111. Associated equipment included a submersible electric pump, an alternating-current generator, and a manifold which split the pump output prior to its flow through the fluorometer. This system is illustrated schembticallv in Figure 4. These components were assembled either in a 16-foot oliboard motorboat or a 26 -foot motor whaleboat. When available, the whaleboat was used and was a much more satisfactory platform because of its greater stability and larger working space.

The fluorometer vas equipped with a "flow-through-door", a device which allows continuous flucroneter readings of the pumped water to be made as it flows through the instrument. A continuous recording of the dye concentration was made on an attached Rustrak recorder. The fluorometer also had a direct reading dial from which readings were manually recorded. Each time a reading from this dial was made, a navigational fix was obtained. This procedure provided for 



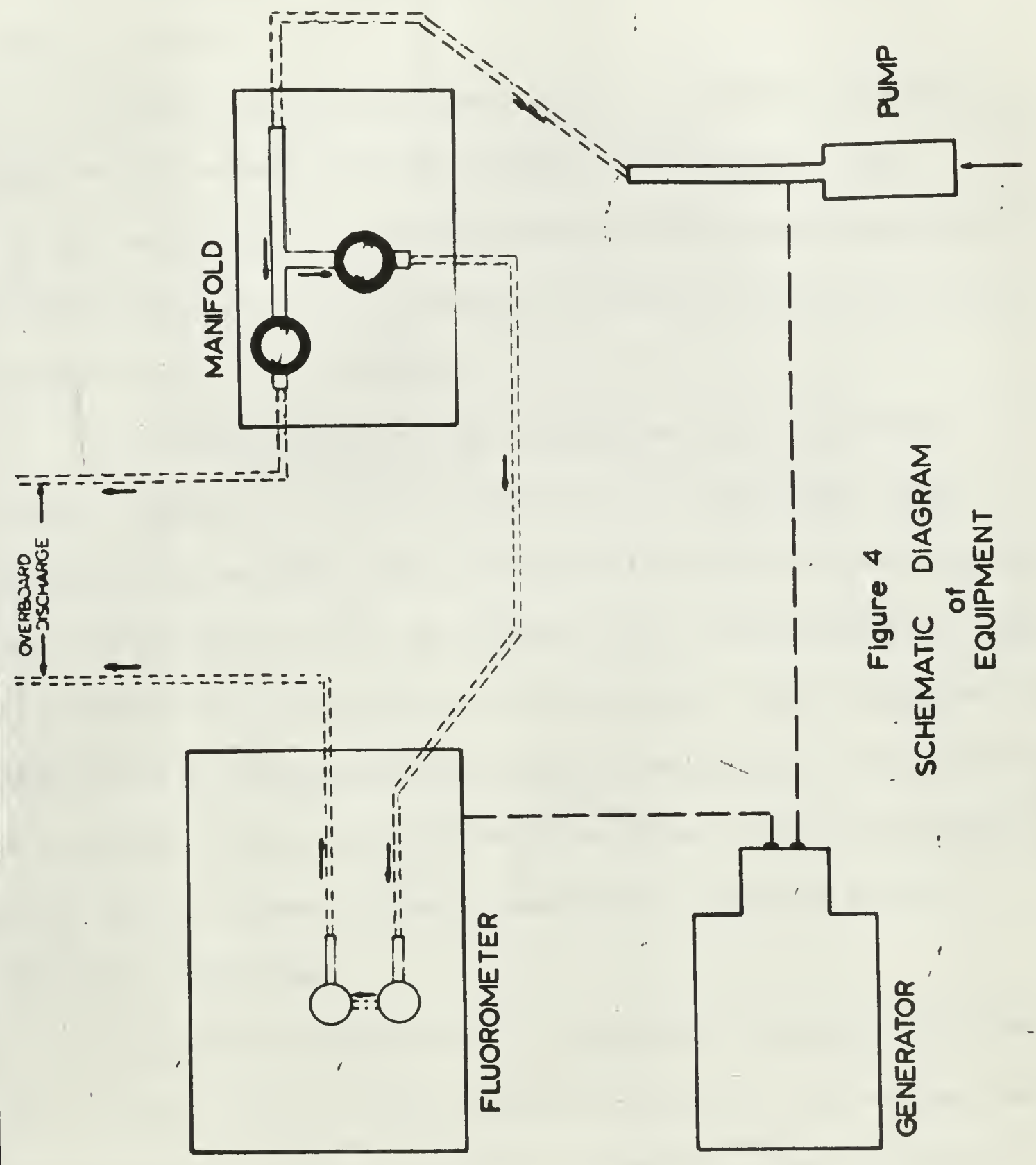



accurate plotting of the Rustrak readings when the data were later placed on charts .

The fluorometer was also provided with a "single-sample-door", which was interchangeable with the "flow-through-door". This "single-sample-door" was used to measure the dye concentration in discrete water samples collected from a rowboat in shallow areas where the fluorometer could not be taken.

Of possible interest to other investigators is the fact that the primary filter used in the fluorometer was G. K. Turner filter number 110-832. The secondary filters consisted of one Corning glass filter of color specification number 3-66 and one 4-97. The primary filter, which is on the incoming (excitation) side of the sample, filters out all but a narrow band of the excitation wavelengths of Rhodamine B, derived from an ultraviolet light source. The secondary filter, on the outgoing side of the sample, passes only those wavelengths in the band at which Rhodamine B fluoresces.

The submersible electric pump, which could be lowered to 25 feet. had a constant output of about six-gallons per minute, and supplied sea water through a polyethylene hose to the manifold, where the flow was split.. Reduction of the flow was necessary in order to prevent cavitation inside the fluorometer and resultant erroneous readings. A small portion was routed from the manifold through the "flow-through-door" of the 

fluorometer where the analysis was accomplished. The remainder was discharged overboard. Folyethylene hose was used because it does not absorb Rhodamine B. Some other types of tubing, such as tygon and rubber, tend to absorb the dye as it passes through, and then release it later, thus yielding erroneous readings (Dowling and Olson, 1953, from Pritchard).

The necessary electrical power to run the pump, fluorometer, and recorder was provided by a portable, gesoline-powered, 117-volt, 60-cycle, alternating-current generator. There were very few voltage fluctuations, and all of these were well within the instrumentation limits of 105 to 130 volts, and 50 to 60 cycles per second. Within these ranges the fluorometer has less than a two per cent error, according to the manufacturer ${ }^{\circ}$ s operating manual.

The dye used in this study was manufactured by DuPont in a 40 -percent acetic-acid solution, and was received in three-gallon containers. It was further diluted in a ratio of orie-to-one with fresh water for use in the outer harbor area. For use inside the marina, one part dye solution was mixed with ten parts fresh water in order to decrease the possibility that the dye might stain boat hulls. No staining occurred. The diluted dye was placed in two-quart plastic containers for ease in handling. In introducing the dye, the containers were emptied over the stern of the boat in the desired pattern. The rate of irtroduction in the case of line sources was controlled only by eye, with the boat maintaining a constant speed. 

The dye as received was more dense than sea water. Even when diluted as described above, it was still slightly more dense than sea water. As a result, upon being introduced into the water, the dye mass sank very slowly while diffusing horizontally. As indicated by fluorometer sampling, a good vertical distribution resulted.

The dye was placed in the water in two basic patterns during the four surveys. For Survey 1, a "point source" of dye roughly 40 feet in diameter was introduced in the outer harbor near the end of the breakwater where, based on bottom topography, the strongest current flow was thought to occur. From the results of this survey, it was felt that a line source, in contrast to a point source, would yield more areal information on water flow in the form of differential movement along the length of the line. Therefore, for Survey 2, a line source was introduced from the western shoreline of the harbor to the seaward end of Wharf No. 1. This crossed the main flow observed during Survey 1, thereby providing continuity between these two surveys. Line sources were again used in Surveys 3 and 4 in order to obtain a cross-sectional profile of the flow across the entire harbor entrance and to trace the flow within the marina.

In order to follow the initial surface movement of the dye during the first two to three hours, when the concentration was sufficiently high to allow the dye to be seen readily from the air, photographs were taken and sketches were made from a helicopter on Surveys 1 and 4 (the helicopter 

was unavallableifor the other surveys). On all surveys, during this initial time period, sketches were also made from the boat on successive passes through the dye area. In addition, fluorometer readings were taken at various depths from 5 to 20 feet along the bourdary in order to check the vertical distribution of the dye.

When the dye becare diffused sufficiently to yield concentrations below the maximum values readable on the fluorometer, continuous readings on the fluorometer were started throughout the area in order to follow the dye boundary and to determine the values and position of the heavier concentrations. The depth of primary interest was five feet.

Drag of the water on the submerged pump and its supporting lines caused the pump to stream aft very close to the surface at boat speeds greater than 1.5 knots, regardless of the amount of line out. Accordingly. survey speeds less than 1.5 knots were maintained. The slow speed meant that each set of traverses of the dye patch took at least 30 to 40 minutes. Therefore, the results of each set did not exactly represent a synoptic picture, although they were treated as synoptic. There was also a 15-second delay in the flow time from the pump to the fluorometer. At the 1.5 knot speed normally maintained, this resulted in a positioning error for the dye of about 40 feet. A correction for this was incorporated when plotting the dye data. 

Fluorometer measurements in the form of dial readings were noted visually and recorded about once a minute, or more frequently when significant concentration changes occurred. The position of the boat was plotted each time a reading was recorded. An attempt was made to maintain a steady course and speed along each traverse. This enabled the 15 -second time lag to be accurately applied and also provided good positioning for plotting the concentration values taken from the Rustrak recorder.

The fluorometer does not provide a direct reading of concentrations, so that a graph had to be constructed for each of the light-path orifice settings available within the fluorometer for use over different concentration ranges. The relationship between the dial readings and recordings to the dye concentration is linear within the range of concentrations measured (relatively low concentrations). This made the graphs easy to construct and use. The readings and recordings were converted, by use of these graphs, to concentrations in parts per billion, and then plotted on a base map of the harbor and contoured (Figures $7,9,10,12$, and 14).

Navigation in the harbor area was relatively accurate. There were many easily recognizable objects along the shoreline which lined up well for use as navigational ranges. These range lires, plus many of the buoys, were plotted on the harbor charts for use during the surveys. In addition, many prominent shore features, pilings on the piers, and wharfs, and the 

floating docks in the marina provided excellent reference points when operating in areas adjacent to them.

The maximum navigational errors were on the order of five feet in the marina, along the piers, and along the shoreline outside the marina. In most of the rest of the harbor area, the maximum error was 25 feet. In the large open area between the end of the breakwater, the sepward end of Wharf No. 2, and the Marina Boundary Wall, the maximum error was possibly as great as 40 feet. In this area, buoys were not very numerous and objects for use as ranges were fewer. When these would otherwise have been visible, many were obscured by the numerous fishing vessels anchored in the harbor. 



\section{RESULTS}

In this section, the dye movement observed during each survey is presented in the form of synoptic charts of the dye boundaries and the dye concentrations, and the pertinent observations and features of each survey are discussed in detail.

In this study, emphasis was placed on the layer of water between the surface and a depth of five feet. During each survey, sampling was also conducted to a limited extent at ten and fifteen feet. Primarily because of time limitations, these deeper tests were not as extensive and therefore not as productive as the surface tests.

Each survey was timed so as to coincide either with a rising or a fal ling stage of the tide, so that circulation during that stage could be studied. The tide stages during which each survey was made are shown in Figure 5. The heights and times of the tides were recorded on the standard recording tide gage maintained by the U. S. Naval Postgraduate School in Monterey Harbor. All tide heights are referred to Mean Lower Low Water.

The weather and sea conditions prevailing during each survey are included in the survey descriptions that follow. Wind observations were obtained by using a hand anemometer in the boat, and from observations recorded by the Harbormaster from an anemometer mounted at an elevation 



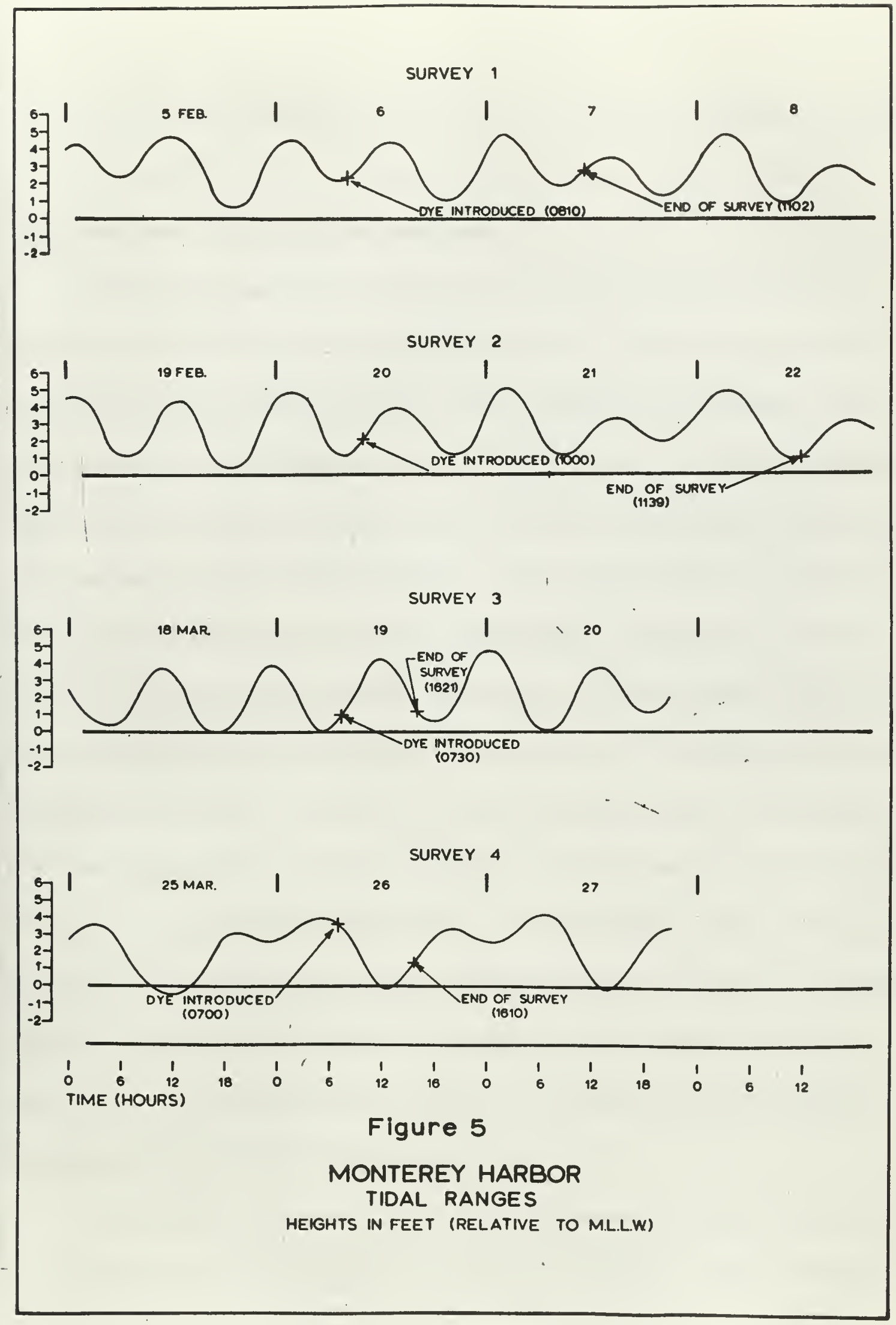



of approximately 50 feet above the water on a building located at the foot of Municipal Wharf No.2. Winds measured concurrently in the two locations were in quite close agreement.

Analysis of the dye observations and measurements led to the employment of two types of data presentation. The first of these is a series of synoptic charts for each survey showing the movement of the dye boundaries with time (Figures $6,8,11$, and 13). These boundaries were determined early in each survey by visual observations, and in the later stages by fluorometer readings. In the early movement of the dye 。 a very clear frontal-type boundary was visually evident around the dye patch. The fluorometer readings taken when crossing these fronts jumped from background levels to readings too high for the fluorometer to measure, in a distance of only a few feet. Later the sharp boundary disappeared, and the margin of the dye patch was then distinguished only on the basis of the dye concentrations recorded by the fluorometer. The boundaries determined by visual observations were used until they became unreliable, then the lowest valued contours from each set of fluorometer readings were used. The visual detection limit of the dye under good lighting conditions was roughly 20 parts per billion.

Background readings of natural fluorescence were taken in the harbor on several days preceeding the surveys and yielded an almost uniformly low 

reading of about 0.2 parts per billion. For this reason, no isolines of a value of less than $0: 5$ parts per billion were drawn on the charts, even though, as previously stated, the fluorometer used was accurate to 0.05 parts per billion. Boundaries across which concentrations dropped from 0.5 to 0.2 parts per billion were usually well defined.

The second type of presentation is a synoptic series of charts showing isopleths of dye concentrations (Figures $7,9,10,12$, and 14). These isopleths were drawn from plotted values of dye concentration taken from fluorometer readings made during the later stages of the surveys .

Unlike current studies using solid floats, the use of dye presents some peculiar difficulties in studying water circulation because the dye is subject to turbulent diffusion as well as advection; however, it also yields more information on diffusion. Thtee methods were employed in this study to separate and measure advection and diffusion. These were as follows:

1. Point-source method.

Movement of the center of a point-source dye concentration on the time-sequence charts for a given survey was used to obtain the mean speed and direction of the flow. In the case of visual observations, the highest concentration was assumed to be located at the geometric center of the observed dye patch. 

The center of the area surrounded by the highest valued concentration isopleth was used for the charts constructed from fluorometer readings (both of these procedures imply a uniform rate of diffusion laterally from the source). Speed was computed using the successive positions of the concentration center and the times involved. The direction of the movement was obtained by assuming that the concentration center moved in a straight line from one observation to the next. This method was applicable only to Survey 1 in which a patch source of dye was placed in the water.

2. Line-source method.

Movement of the geometric centerline of dye patches which resulted from line sources yielded the mean speed and direction of movement of different parts of the line in the same manner as described above, and thus provided additional information on differential flow. Information was also obtained on the rate of diffusion, which was expressed in terms of the rate at which a given isoline of dye concentration progressed out from the moving centerline of the maximum concentration. This method was used only in Survey 2 . 

3. Boundary-movement method.

The mean speed of water flow at the boundaries of the dye patches was computed by subtracting from the rate of boundary movement, a fixed rate of diffusion computed by the use of method (2) above for Survey 2 (discussed later). The weakness of this procedure lies in the application of a constant diffusion rate to all surveys; however, this assumption does not appear unreasonable in view of the fact that the scale and intensity of the horizontal water motions in the shallow harbor were probably similar during all of the surveys due to the boundary limitations on turbulence imposed by the dimensions of the harbor. The mean direction of the flow was assumed to be normal to the boundary line. In several instances the flow was partially divided, as in Survey 1 where lobe-like extensions developed (Figures $6 \mathrm{D}$ and $6 \mathrm{E}$ ). In these cases each path or lobe was followed in order to compute the speed and direction of the current. 



\section{Description of Individual Surveys}

Survey 1: February 6 and 7, 1965 (Figures 6 and 7)

At 0810 on February 6, approximately 1.5 gallons of dye solution, diluted one-to-one with fresh water, were introduced into the harbor. The dye was sown in a patch approximately 40 feet in diameter, the center of which was south of the breakwater, as indicated in Figure 6A. This site was selected for the initial survey because bottom topography adjacent to the breakwater is the deepest in the harbor, and it was felt that this deeper zone was the most likely place to expect strong currents during a changing tide (Figure 3 ).

The time span of the survey was selected so as to extend over the full duration of a rising tide when flood currents were to be expected. The dye was introduced 45 minutes after a low tide of 2.4 feet; the succeeding high tide was 4.3 feet at $1248^{\prime}$ (Figure 5). Weather during the survey was clear, with high scattered clouds. A steady northwest wind of about 20 knots persisted until shortly after noon, when the wind dropped to 12 knots from the northwest and remained at that velocity for the rest of the day.

The wind had a strong effect on at least the surface layer during the early part of the survey. Over half of the dye according to photographs and visual observations taken from the helicopter, was carried in a winddriven flow out of the harbor and into the choppy bay in the direction of 

the wind. The dye was streaked out in long thin fingers which had their axes oriented in the approximate wind direction. The ends of the fingers had a feathery appearance with no sharp gradients visible anywhere. Very small cumuliform eddies, on the order of a few inches in diameter, were observed in some areas.

The remainder of the dye was carried along the breakwater toward the inner harbor in opposition to the wind, and presumably represented tide-driven flow associated with the flooding tide. The dye advanced into the harbor for at least the first hour with a sharply defined front that had a coarse cumuliform appearance. Gradually, the choppy action in the quieter water behind the breakwater was sufficient to break up this effect, and the dye mass assumed the feathery form observed in the dye which had been blown from the harbor into the bay.

Aerial photographs and visual observations from both the helicopter and the boat also revealed a small tongue of dyed water which moved as a narrow flow around the seaward end of the breakwater and directly into the wind (Figures $6 \mathrm{~B}$ and $6 \mathrm{C}$ ). This appeared to represent a counterflow developed in response to the wind-driven current passing the breakwater. This flow, and the large movement of dye into the bay which resulted from the wind-driven current, were observed only at the surface, because weather conditions rendered it impossible to venture beyond the protective shelter of the breakwater in order to take fluorometer readings at depth. 

Dye-front movements within the harbor revealed a counterclockwise surface flow, as indicated by progression along the western shoreline of the several centers of concentration that later appeared (Figures 7A through 7D). The average initial speed of the centers 。 from 0810 through 0935 , was about 60 feet per hour, or 0.010 knots (Figures $6 \mathrm{~A}$ and $6 \mathrm{~B}$ ). The average speed of the centers then increased to about 160 feet per hour (0.026 knots) from 0935 through 1130 (Figures 6C and 6D). Between 1130 and 1230 the data obtained made it difficult to follow the movementlof the centers. From 1230 to 1530 the dye center moved at a mean'rate of 270 feet per hour, or 0.044 knots (Figure 6E). These speeds indicate a tidal origin, since the current flow was weak sh ortly after slack water ${ }^{\text {then }}$ the incoming tide progressed, the current speed increased considerably .

In addition to the flow along the breakwater and the western shore, there was a current which split off and flowed across the center portion of the harbor. This flow is revealed by the lobe pattern and associated heavier dye concentration shown in Figures 7C and 7D, and by the boundary movement in Figures $6 \mathrm{D}$ and $6 \mathrm{E}$. The speed of this current, as computed from the movement of the centers of concentration from 1130 to 1530 , was constant at about 280 feet per hour ( 0.046 knots).

In addition to the surface movement described above, attempts were made to follow the subsurface currents by means of fluorometer readings. 

These readings, taken at 10 and 15 feet, were too infrequent and too incomplete to contour; however, each subsurface investigation indicated that the underflow followed that at the surface.

On February 7 fluorometer measurements were made to determine the distribution of the dye that had been placed in the harbor on the previous day. The weather from the early morning hours until the late afternoon was clear with a light breeze. By 1600 the breeze had ceased and a heavy fog settled over the harbor. Low tide occurred at 0830 , with a height of 1.9 feet, and a high tide of 3.5 feet occurred at 1348 (Figure 5). Analysis of the February 7 data, collected in four boat runs from early morning until late afternoon at depths of $5,10,15$, and 20 feet, revealed that the dye was quite evenly distributed throughout the harbor, including the marina. The maximum readings were 1,7 parts per billion, with the majority being around 1.0 part per billion. The readings taken at these depths were, in almost all cases, the same as the surface readings, indicating uniformity in the vertical as well as the horizontal distribution . A channel exists in the bottom topography on the harbor side of the breakwater (Figure 4). This channel was earlier attributed to current scour, but the currents measured in this area were not particularly strong. It now appears that the channel can be explained as a result of the geometry of the placement of the breakwater, since, if contours are drawn across the breakwater, they indicate continuity from one side to the 

other. These contours, which are partially illustrated in Figure 3, were taken from a 1963 survey of the U. S. Army Corps of Engineers (San Francisco District).

Survey 2: February 20,21, and 22, 1965 (Figures 8,9, and 10)

At 1000 on February 20, approximately 1.5 gallons of dye solution, diluted one-to-one with fresh water, were introduced into the harbor. The dye was sown on a line extending from a point off the shore northwest of Municipal Wharf No. 1 to the end of the wharf (Figure 8A). This location was chosen because it was desired to continue tracing the current observed on the previous survey. Because Survey 1 showed a well-defined flow along the western shore of the harbor, it was considered desirable to examine the effect of both the groin and the Marina Boundary Wall on the continuation of this flow and on harbor circulation in general. Of particular interest was the possibility of inflow to the marina.

The dye was introduced as a line source so that differential flow, if present, could be noted. The time for introducing the dye was chosen so that the incoming tidal current would be flowing when the dye was sown. A low tide of 1.2 feet occurred at 0754 , and the next high tide was 3.9 feet at 1336 (Figure 5). The weather was clear with only a few high scattered clouds. Calm wind conditions prevailed throughout the day.

The calm wind conditions and absence of waves in the harbor afforded an ideal opportunity to closely observe the initial diffusion of the dye. 

It was evident from watching the dye as it was poured into the water that it distributed itself through the whole water column during the first few minutes. Fluorometer readings taken some time later at 5 and 10 feet indicated a uniform dye concentration vertically. The dye sank slowly into the water while continuously diffusing horizontally. A continuous stream of puffy billows formed around the core of the dye, and grew out from the line source in a manner which greatly resembled the formation of cumulus clouds. Billow grew upon billow with a rate of advance which was easily discernable to the eye. Similar observations of this process were reported by Shönfeld and Groen (1961) .

The boundary of the dye approximated a front rather than a broad area of slowly decreasing concentration. This visual observation was borne out by fluorometer readings across the boundary. During the early portion of this and the other surveys, fluorometer readings indicated very high gradients of dye concentration in the space of only a few feet. Even after two hours, the distance between background readings and very high concentrations was only about 10 feet.

A rate of horizontal diffusion was calculated from Figures $8 \mathrm{~A}$ and $8 \mathrm{~B}$ by assuming that the dye boundary diffused at an equal rate in both directions from the initial line source, thereby allowing a subjective estimation of the position of the centerline of concentration. This estimate was necessary because no concentration measurements for the center of the area could 

be collected since the concentrations were greater than the maximum limit of the fluorometer. The width of the dye patch was measured at various places at discrete time intervals. The rate of diffusion was then calculated from the change in distance between the centerline and the boundary over the time involved. Final values were obtained by using the three bibest visual plots of the expanding dye patch. The three values were nearly equal and averaged 140 feet per hour $(0.023$ knots $)$.

As indicated by concentration boundaries and lobes shown in Figures $8 \mathrm{~A}, 8 \mathrm{~B}, 9 \mathrm{~A}, 9 \mathrm{~B}$, and $9 \mathrm{C}$, the strongest current flowed from the area near the end of Municipal Wharf No. I toward the southeast along the seaward side of the Marina Boundary Wall. By subtracting the computed diffusion rate of 140 feet per hour from the speed of the boundary movement, this current was calculated to have an average velocity of 210 feet per hour $(0.035$ knots $)$ for the period 1030 to 1230 . After this time, movement slowed until it was only slightly more than the rate of diffusion.

Another branch of the current flowed toward the marina entrance and under Municipal Wharf No. 1 with an initial velocity of 230 feet per hour, $(0.038$ knots) over the period 1030 to 1100 . After this there was a short reversal, and then advection in this area ceased. Only a small amount of dye penetrated into the marina. Most of this is considered to have been the result of diffusion, based on the calculated diffusion rate of 140 feet per hour. 
A third noticeable movement was perpendicular to the original line in a southwest direction. This flow was contained by the groin located in the southwest corner of the harbor. At low tide, this groin is completely exposed, and at high tide, it is covered only by a few feet of water.

Few readings were taken at depths greater than five feet during this survey because of time limitations and also because most of the area into which the dye penetrated was less than ten feet deep. However, readings were taken at depth in the outer harbor and along the Marina Boundary Wall, but only at infrequent intervals and only to verify that the movement at depth was approximately the same as that at the surface. In most cases these readings were too sparse to contour adequately and so no details are presented.

On the second day of the survey, February 21 , fluorometer readings taken at 5 and 10 feet on traverses throughout the harbor indicated that most of the dye had been flushed from the harbor (Figure 10). The heaviest concentration noted was four parts per billion along the shore northwest of Wharf No. 1. By the third day, February 22 , fluorometer readings indicated that concentrations in the harbor were down to the background level. These readings were taken at 5,10 , and 15 feet in all areas of the harbor and marina. 

Survey 3: March 19, 1965 (Figures (11 and 12)

At 0730 on March 19, 1.5 gallans of dye solution, diluted one part dye to one part fresh water, were introduced in a line source. This line extended from the breakwater to the marina entrance (Figure l1A). A second line, consisting of one part dye in ten parts fresh water, was placed inside the marina entrance, parallel to Municipal Wharf No. 1 (Figure 11B). These locations were selected in order to examine the flow across the entire harbor entrance and the flow into the marina during flood tide. The time span of the survey was selected so that it would extend over a period of rising tide when currents flowing into the harbor were to be expected. The dye was introduced one hour and 48 minutes after a low tide of 0.2 feet. A high tide of 4.2 feet occurred at 1154 , followed by a low tide of 0.6 feet at 1743 (Figure 5). At the time of the dye injection, the weather was very foggy, with no wind. Soon afterward the wind began to pick up, and by mid-morning the wind had increased to eight knots from the northwest. This wind persisted for the rest of the day.

The major portion of the dye which was introduced in the outer harbor was observed to move out into the bay (Figure 11A). Much of it was carried around the end of the breakwater against the eight-knot wind, as a counterflow similar to but smaller in scale than that occurring in Survey 1 . Because the tide was rising during the survey, there must have been flow into the harbor at subsurface depths. However, no subsurface dye measurements were made that might have indicated such an inflow. 
A possible explanation is offered by the fact that densities calculated from salinity and temperature measurements taken by R. H. Miller (personal communication) on March 21, on the bay side of Municipal Wharf No. 2, indicated a large increase in density in the water layer between zero and five feet. Frorn this level to the bottom there was only a small increase in density. Wind and weather conditions on that day were almost identical to those on March 19, so it is quite possible that the density structure was almost identical on these two days. If this were the case, it is quite possible that the lighter surface layer was blown out into the bay and that the total inflow occurred in the subsurface layer.

Movement of the dye line placed in the marina indicated the penetration of a dye concentration lobe farther into the marina (Figure 11B). No rotation was observed, and the rate of movement of the dye front into the marina was very small, approximately 100 feet per hour ( 0.016 knots) for about.the first four hours of the survey .

\section{Survey 4: Match 26, 1965 (Figures 13 and 14)}

At 0700 on March 26, approximately 0.1 gallon of dye solution, diluted one part dye solution to 10 parts fresh water, was introduced in two lines inside the marina. One line was sown parallel to Municipal Wharf No. 1 and the other extended from Municipal Wharf No. 2 along approximately two-thirds of the length of the main channel inside the marina (Figures 13A and $13 C)$. These areas were selected in order to further investigate the 

circulation associated with tidal currents within the marina. The survey extended over the entire interval of an ebbing tide and for most of the following flooding tide.

The dye was introduced two hours and six minufes after a high tide of 4.1 feet; the following low tide was -0.3 feet at 1242 . Weather during the survey was poor, with occasional drizzle. Cloud conditions ranged from broken to complete overcast during the day, with a light breeze in the early morning increasing to nine knots from the northwest by 1300 .

A third dye line, extending from the breakwater to the marina entrance . was introduced at 1310 . The reason for introducing this line was to repeat, under similar rising tide conditions, the test conducted at this location during Survey 3, wherein the bulk of the dye moved out of the harbor against the flooding tide. Aerial photographs of the line source in the outer harbor, taken from a helicopter between 1330 and 1530 , indicated that the end of the dye line near the marina entrance did not move very much. The remainder of the line rotated clockwise about 45 degrees under the influence of the wind and extended itself far out into the bay. At this stage the line consisted of a series of tongues oriented parallel to the wind. The effect was similar to that of overlapping shingles. As the overall behavior of the dye was very similar to that observed on Survey 3 , including the counterflow around the end of the breakwater, no fluorometer measurements were made in this area and no figures are shown. Instead, attention was concentrated on.the area inside the marina. 

The dye movement within the marina, depicted as dye boundaries at specific times, is illustrated in Figures 13A through 13C. The synoptic dye concentration patterns are shown in Figures 14A through 14C. The figures reveal that within the marina, the dye line in the main channel diffused in a concentric pattern during the falling tide. There was a slight motion of the entire mass as a unit toward the marina entrance, but no rotation occurred. On the rising tide, the pattern rotated slowly in a counterclockwise direction. The strongest dye concentration moved along the Marina Boundary Wall toward the marina entrance.

The line source which had been placed next to Municipal Wharf No. 1 was carried under the wharf and out of the marina by the falling tide (Figure 13C). Movement of this patch ceased when the tide changed from ebb to flood, and no further movement was observed for the remainder of the day. 



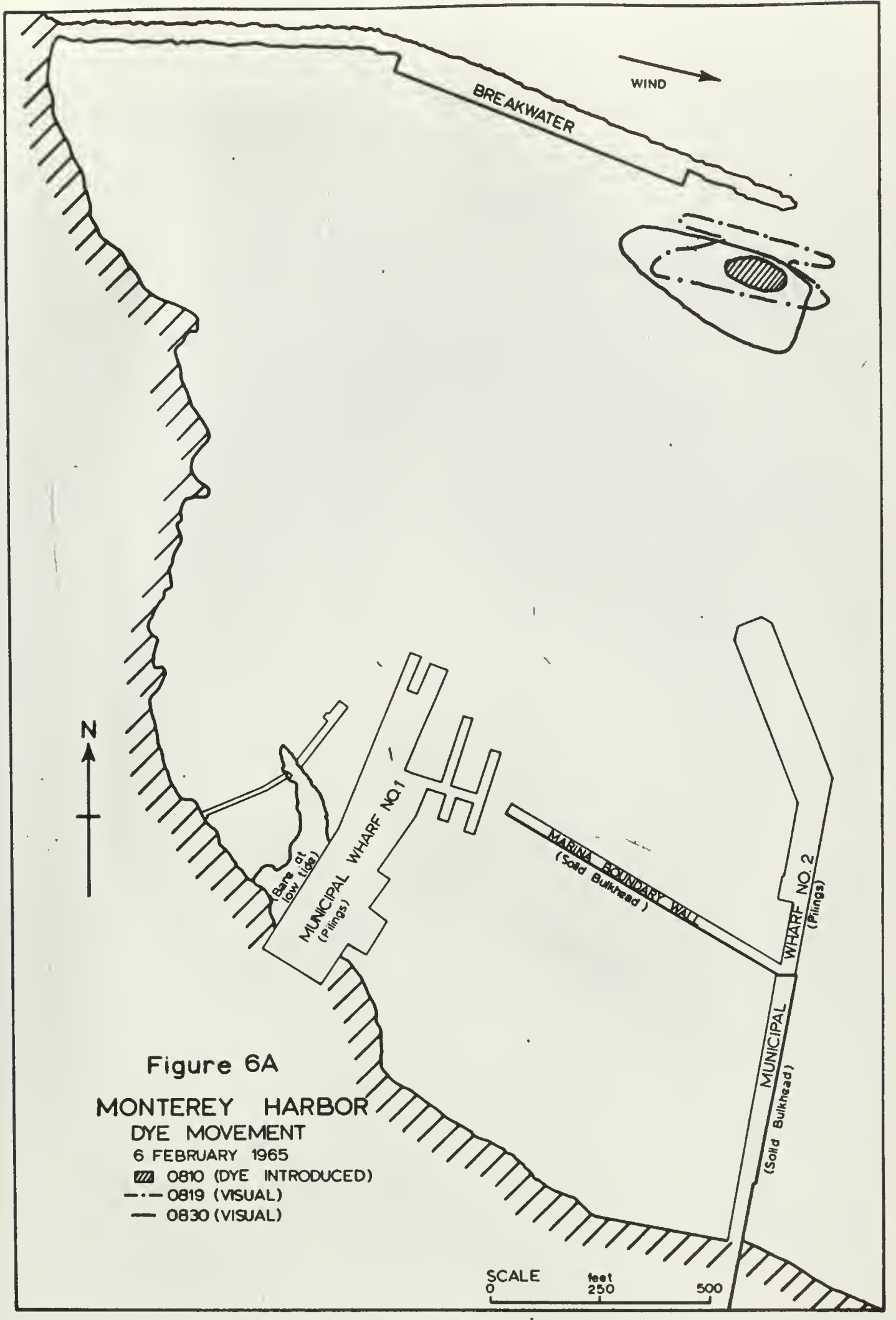





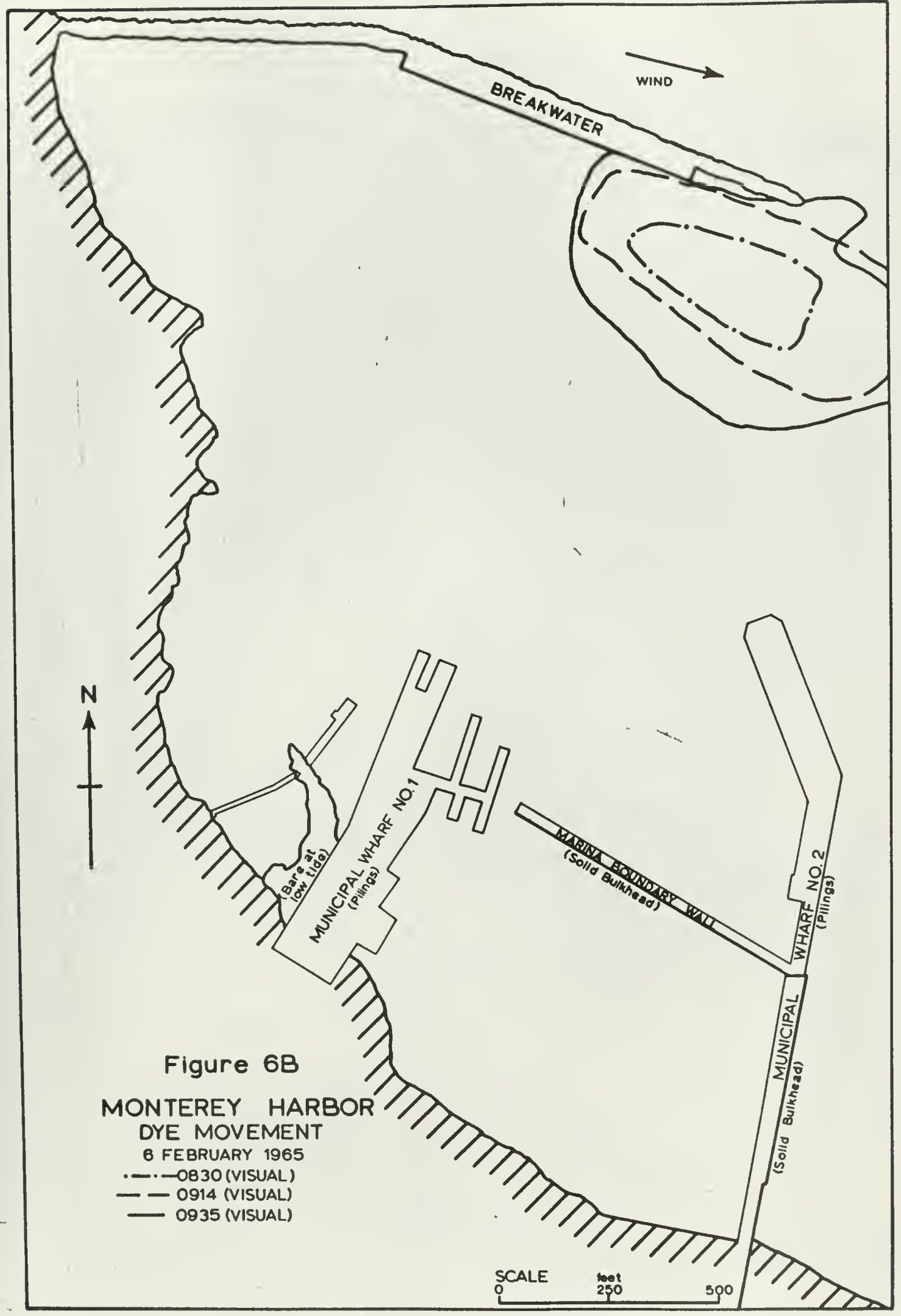





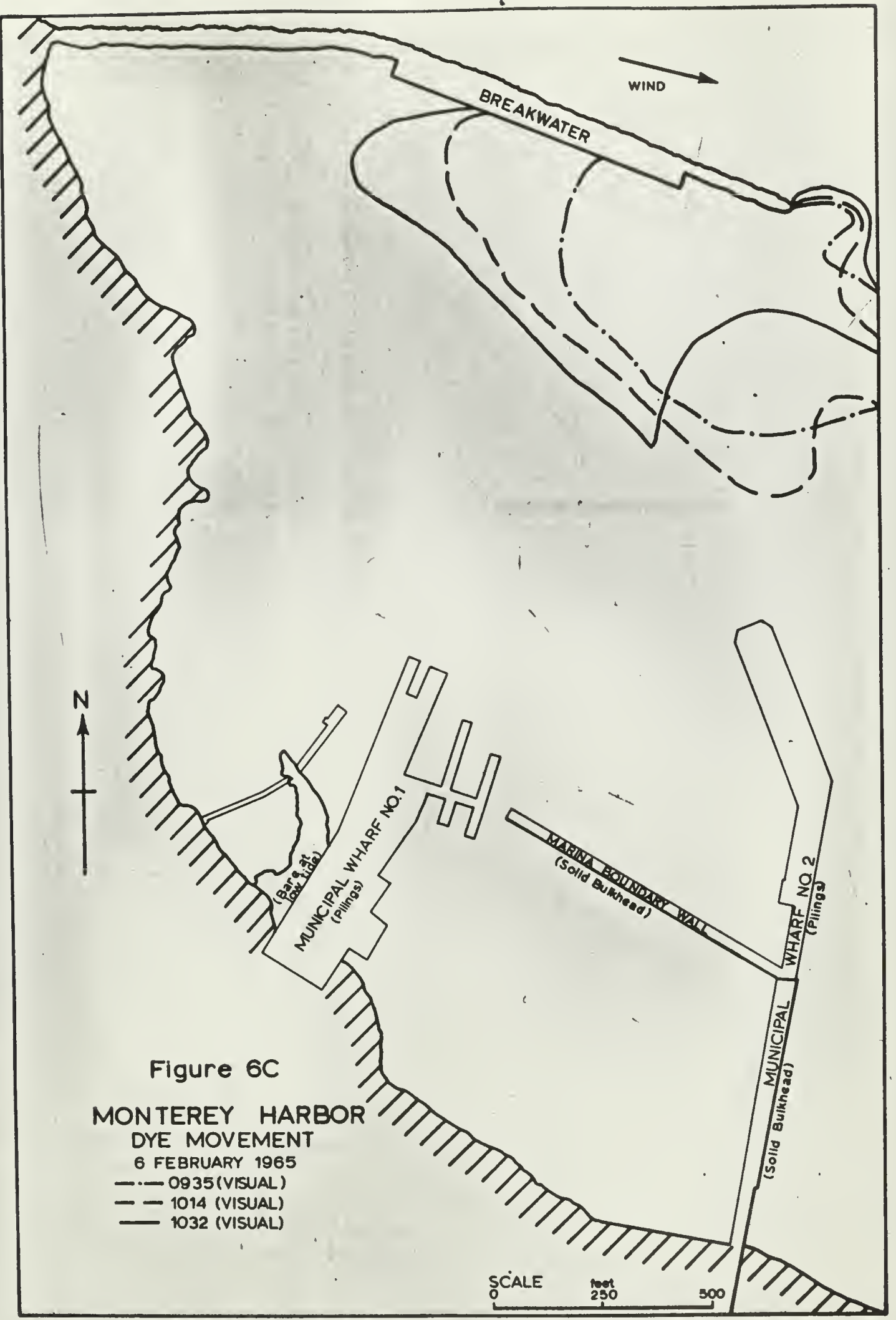




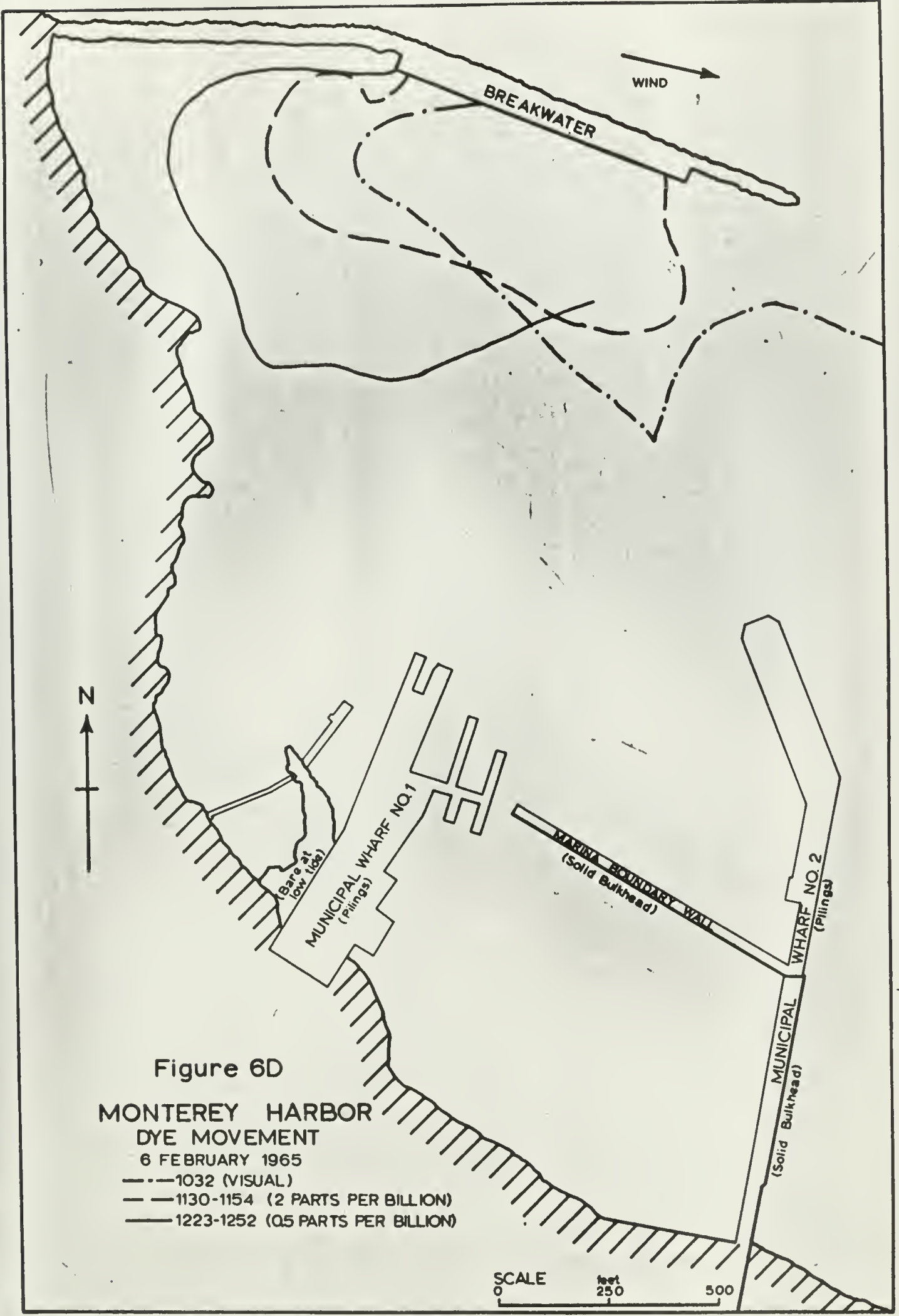





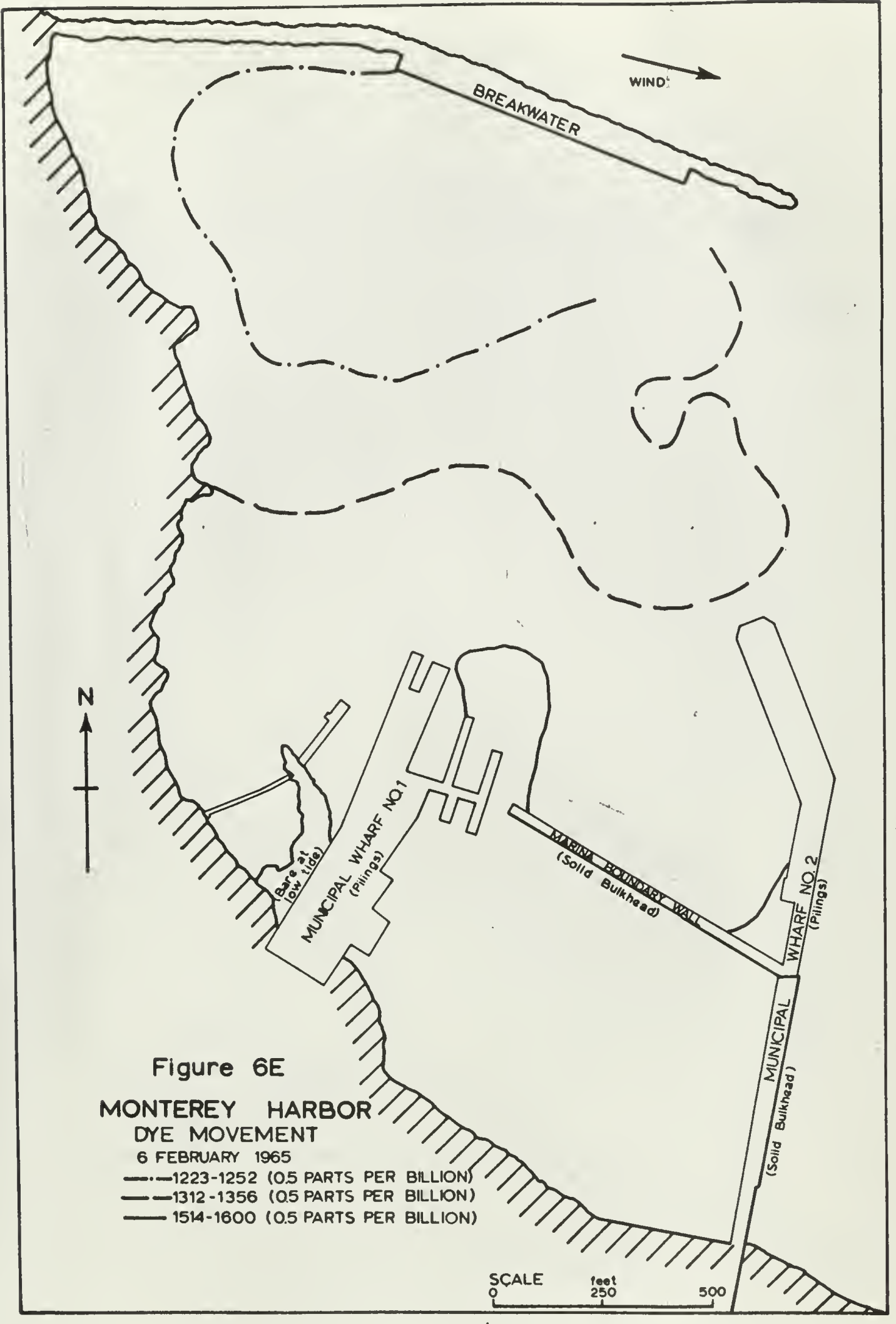




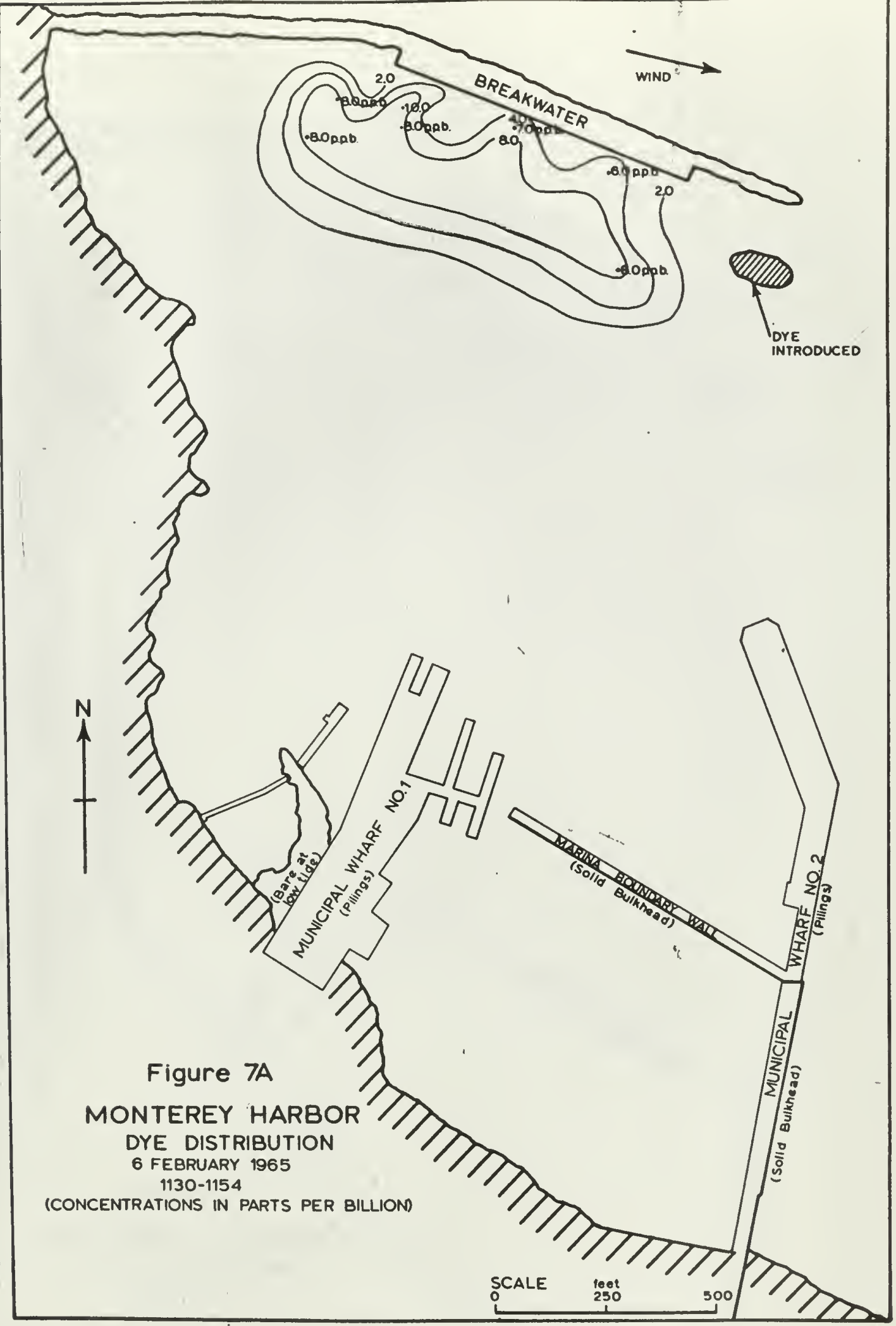





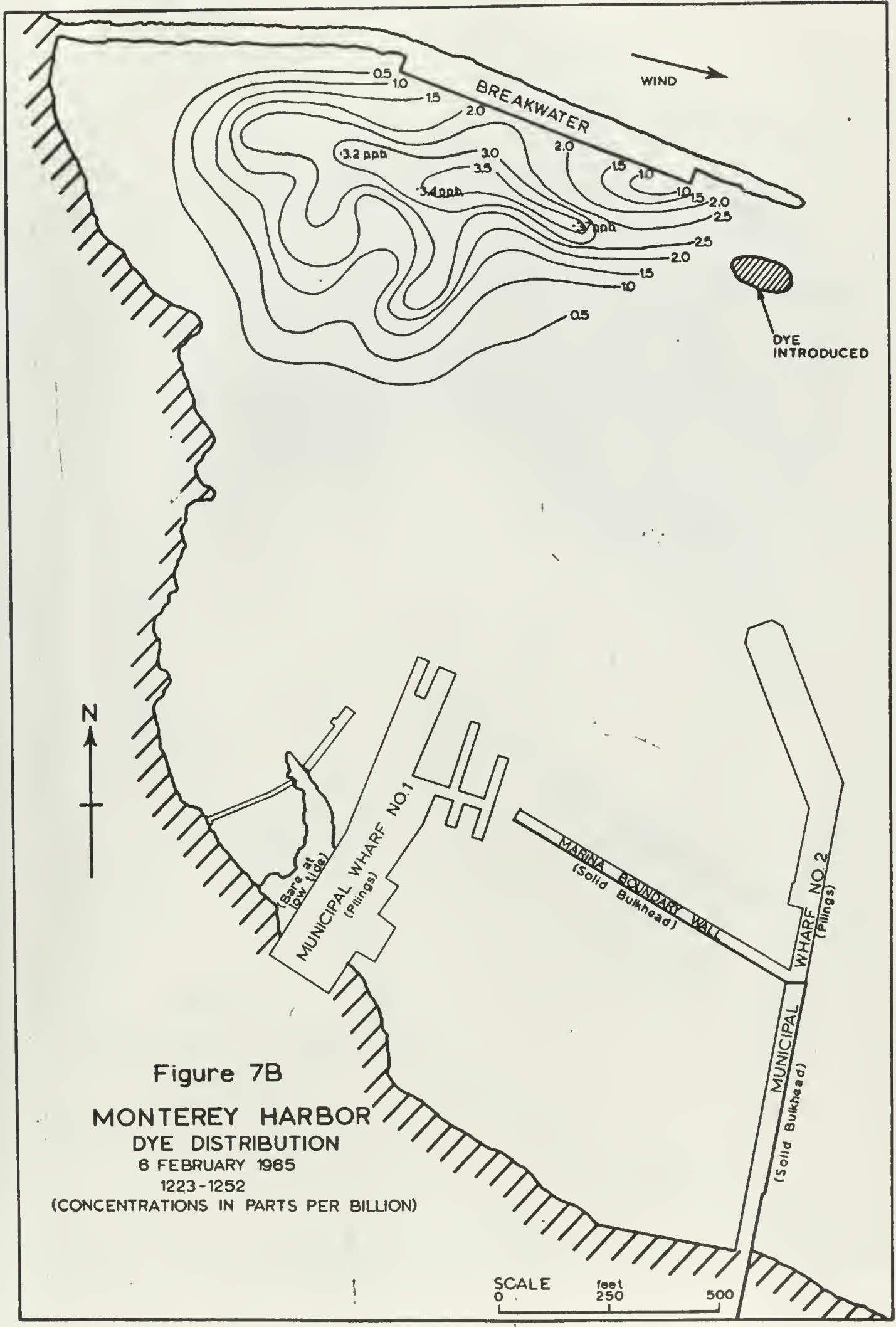





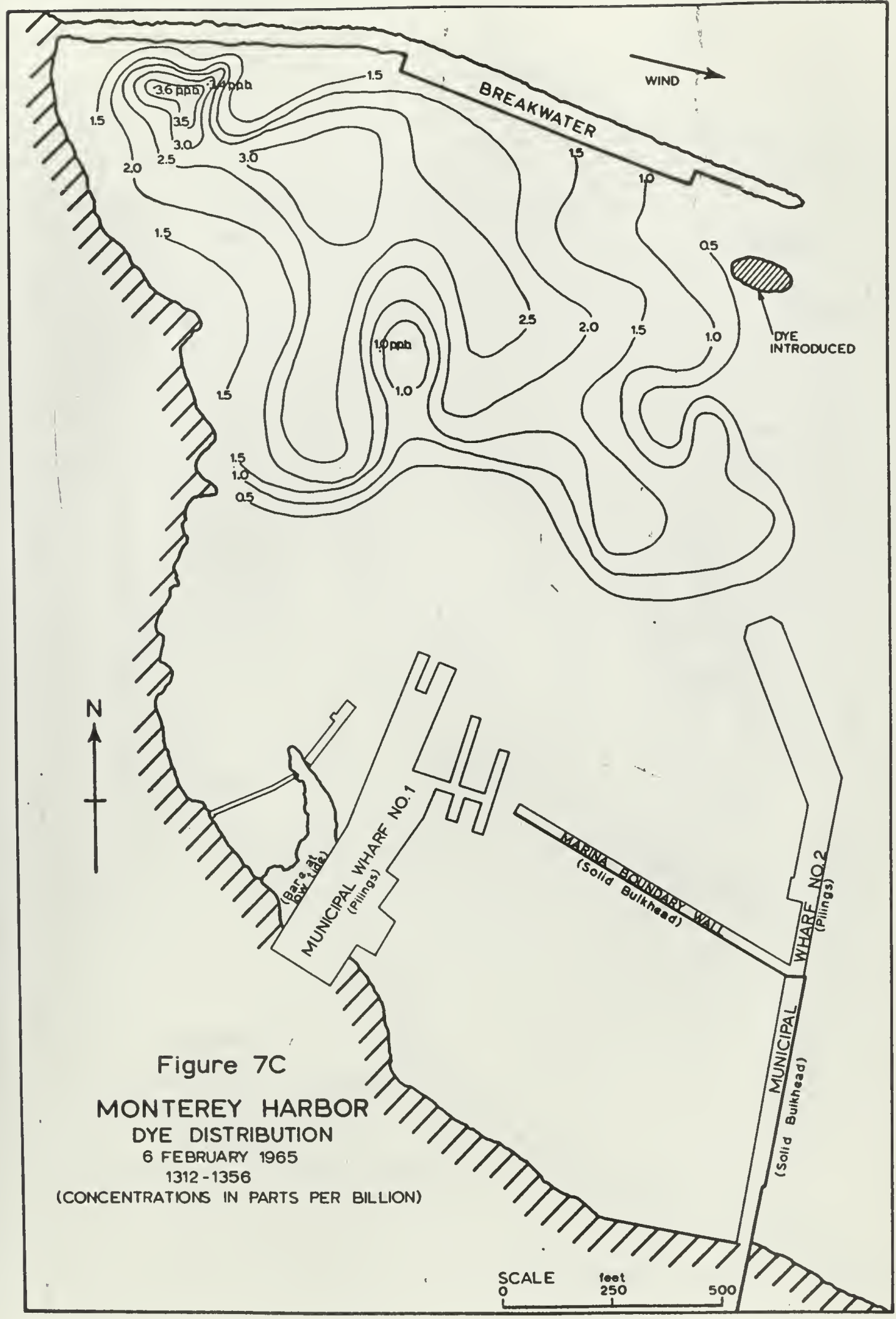





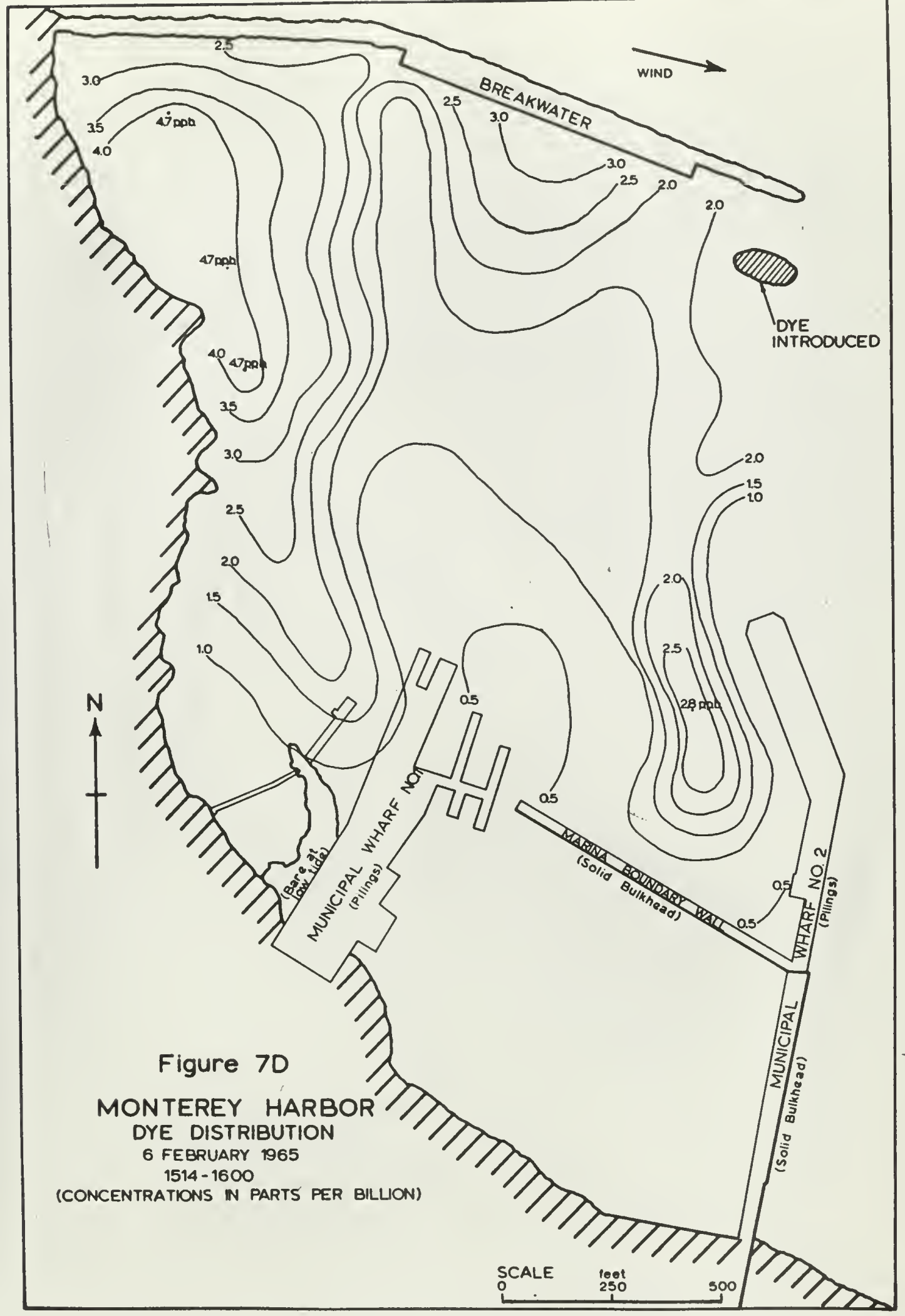





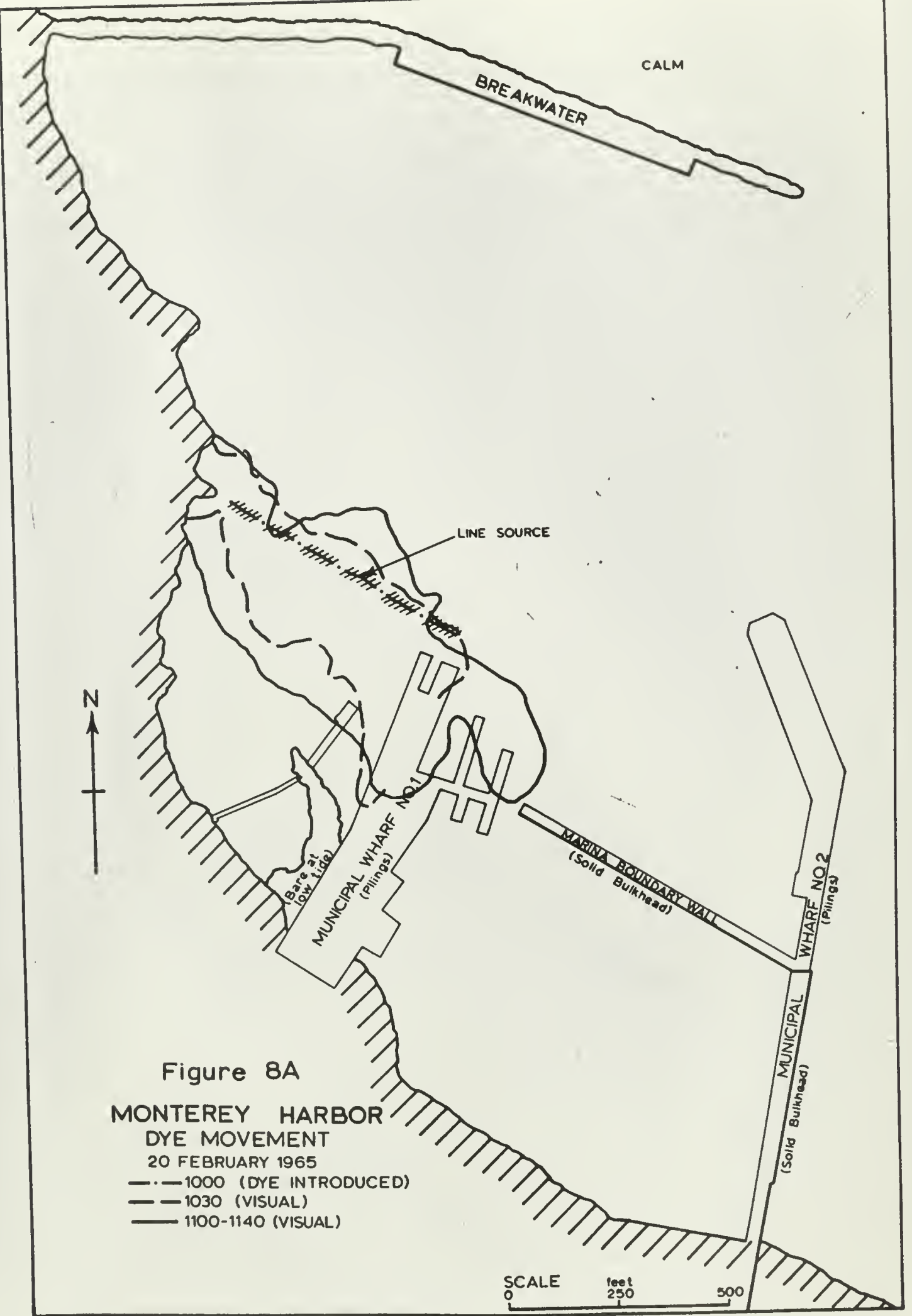





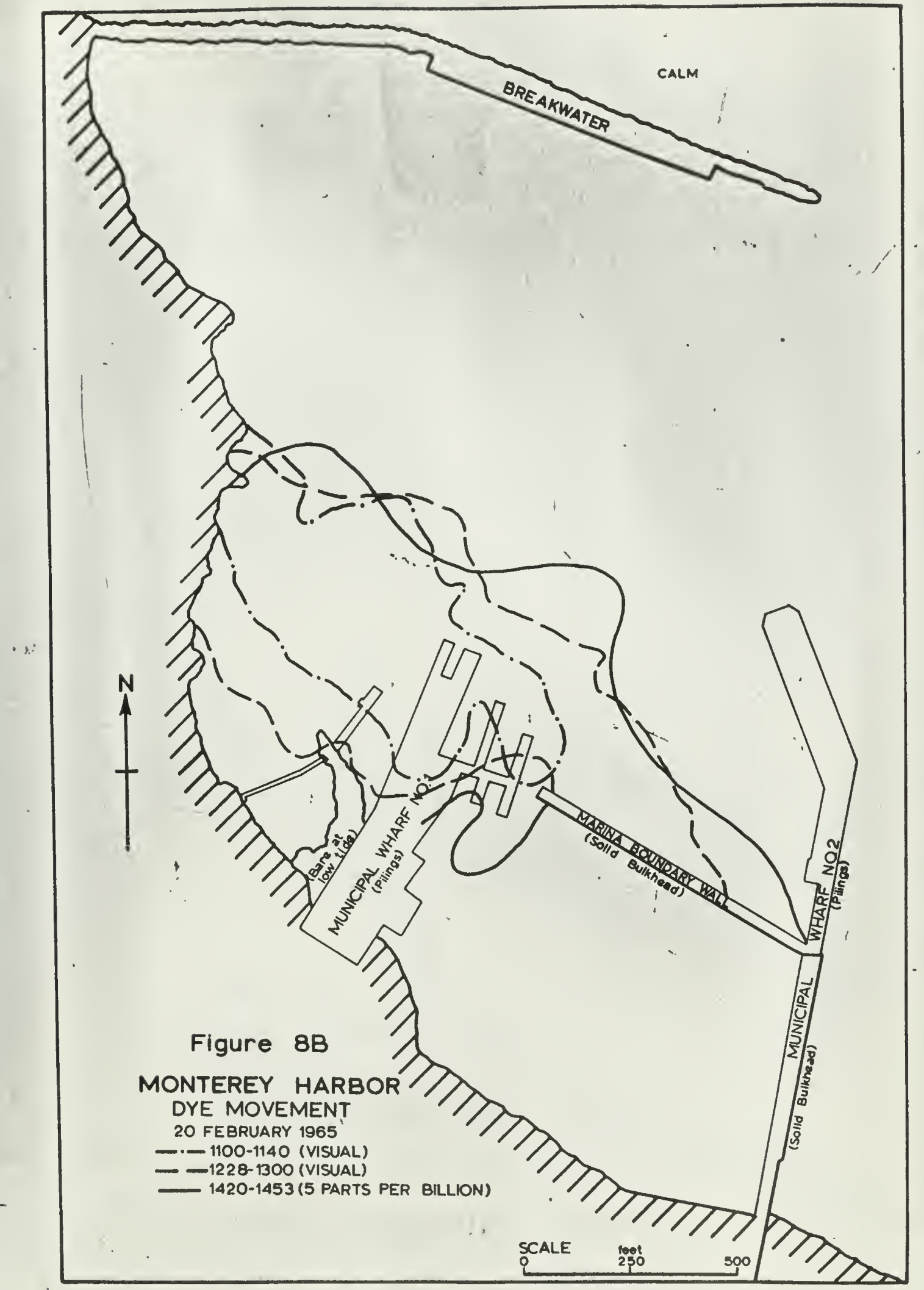





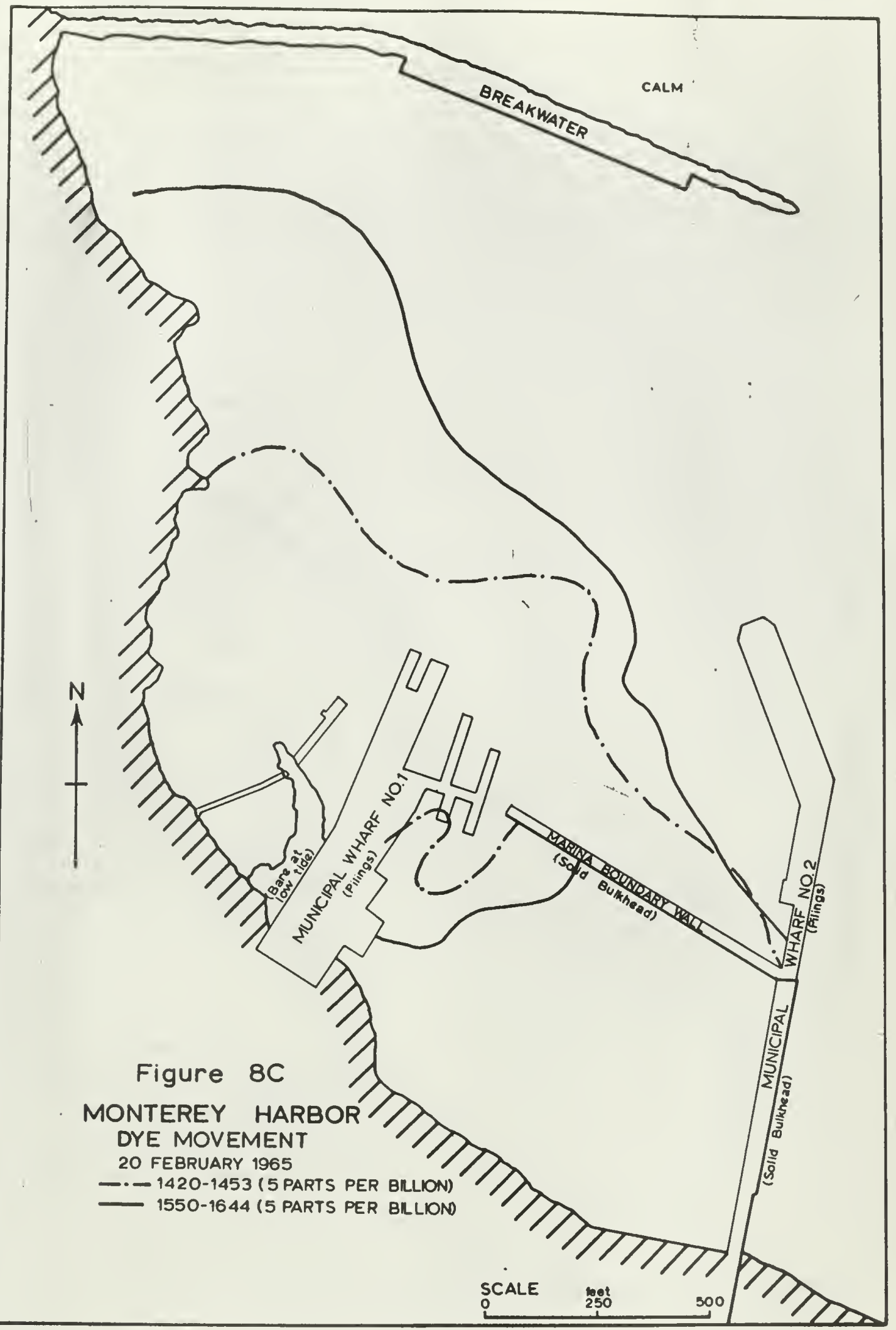





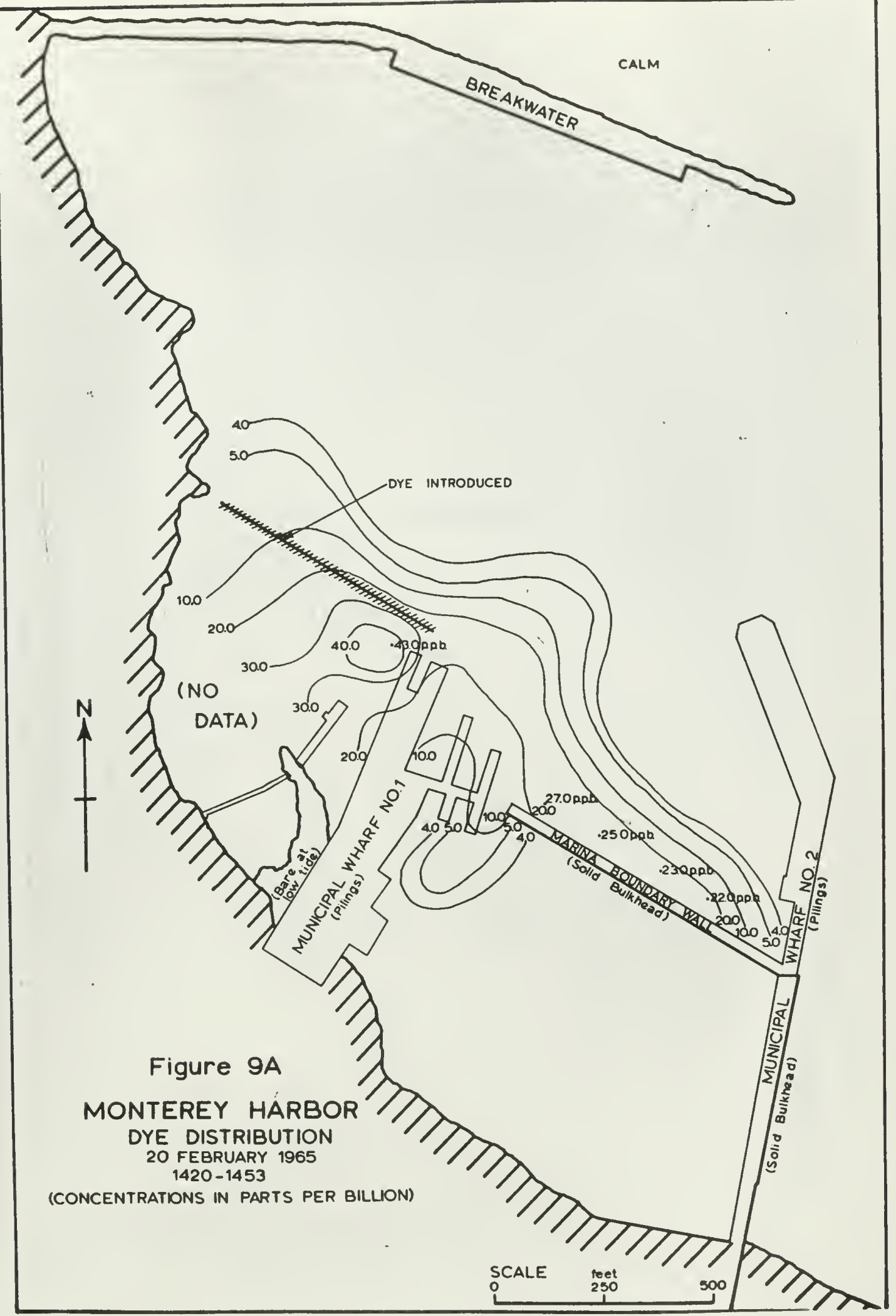




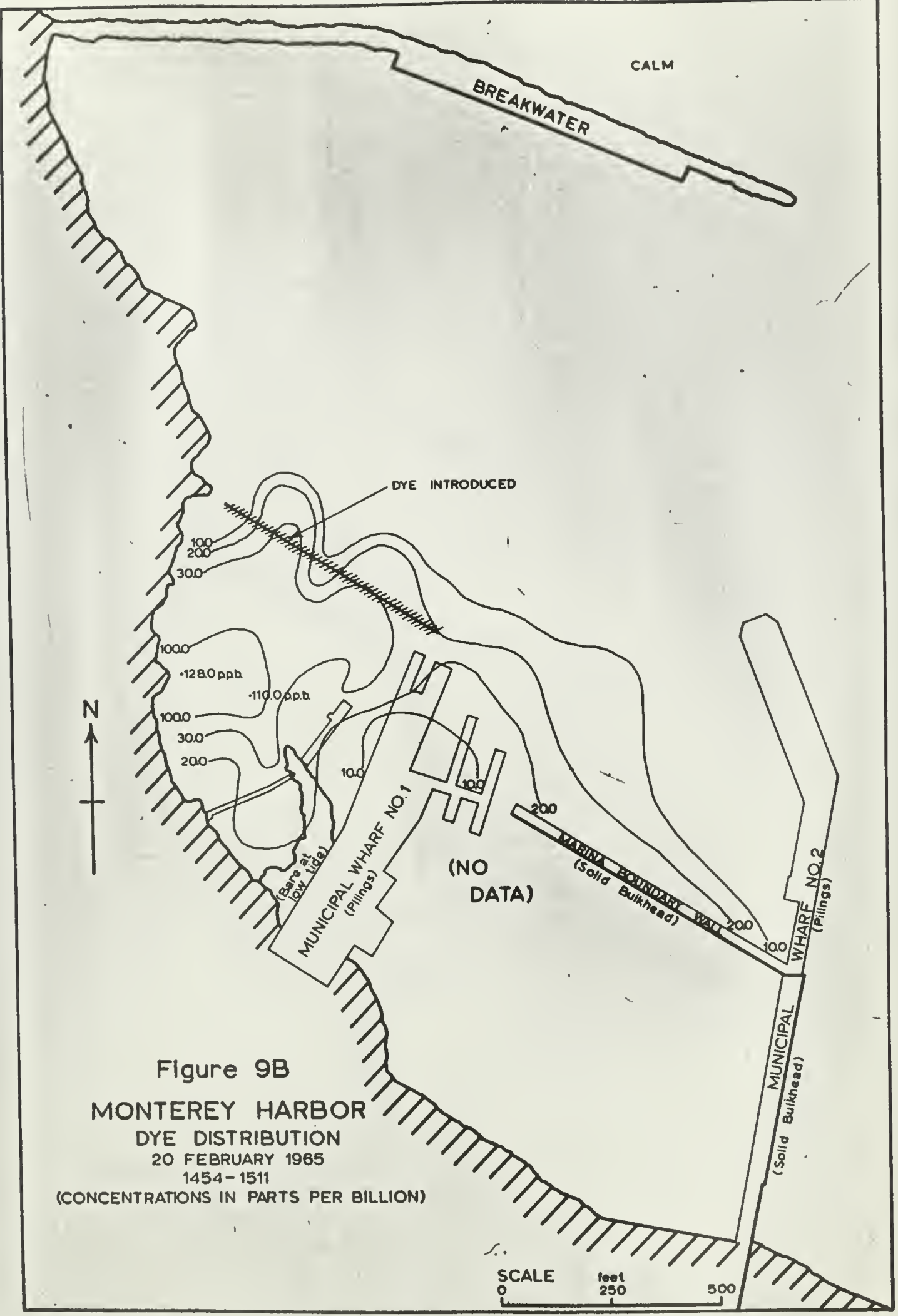




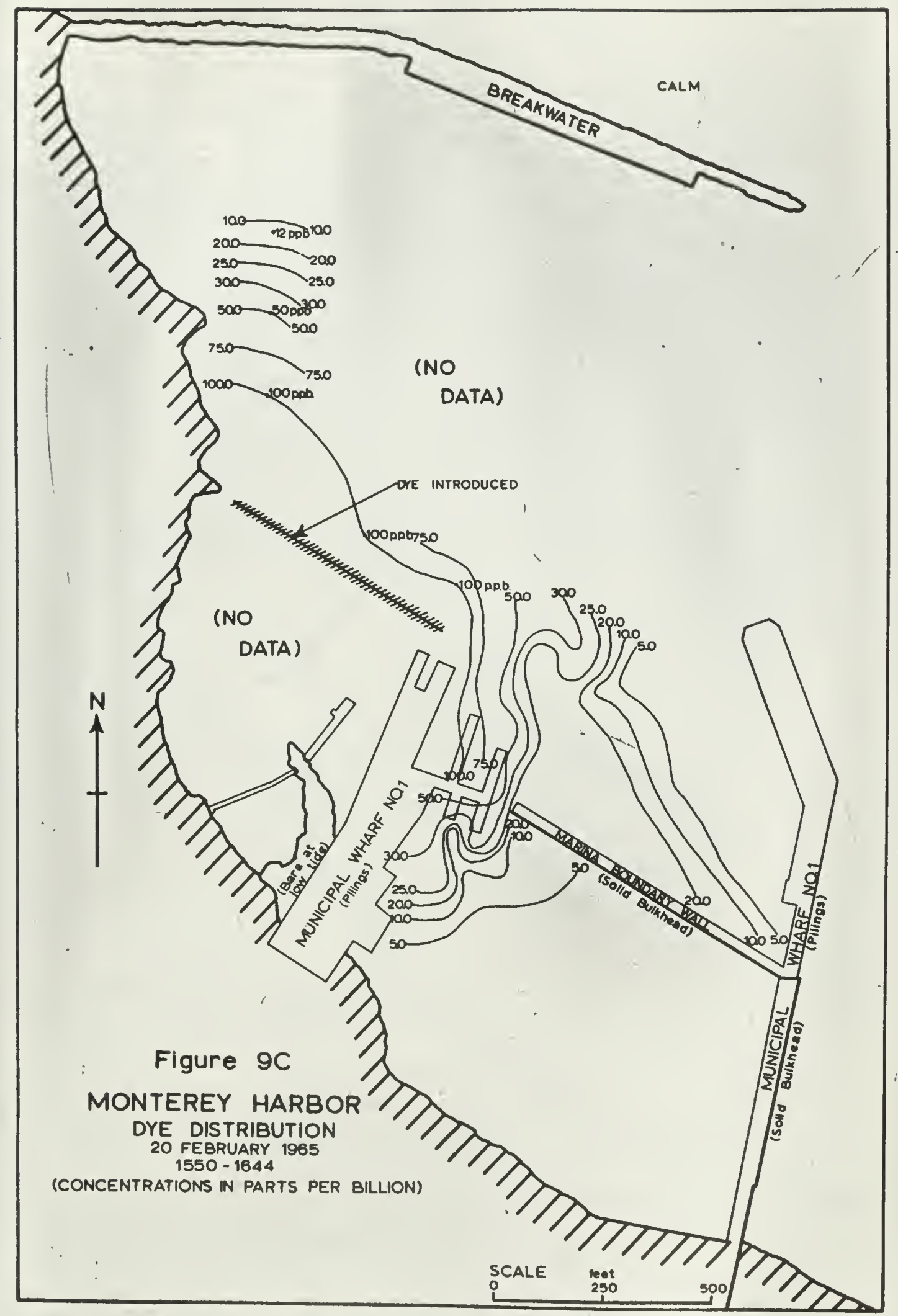




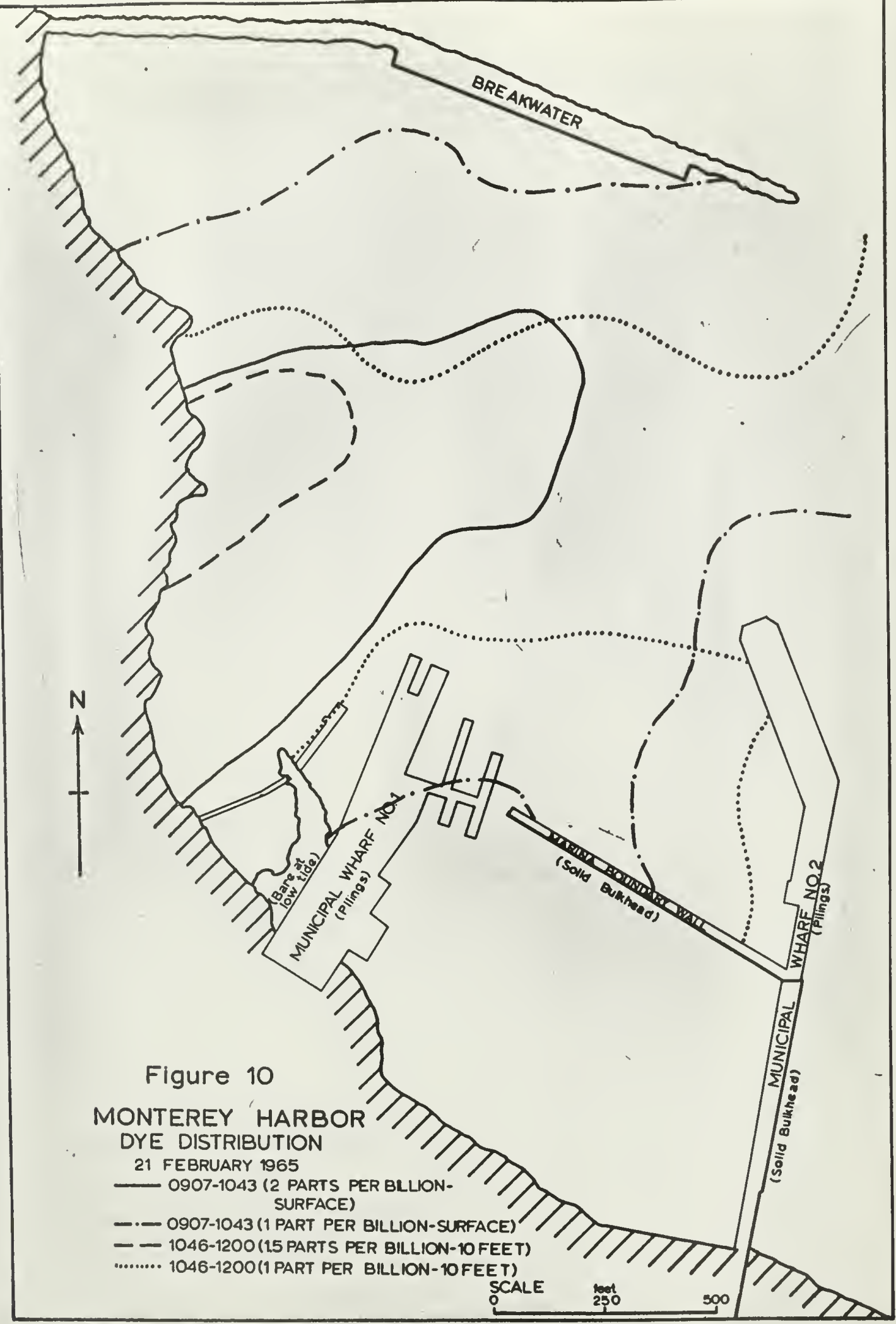




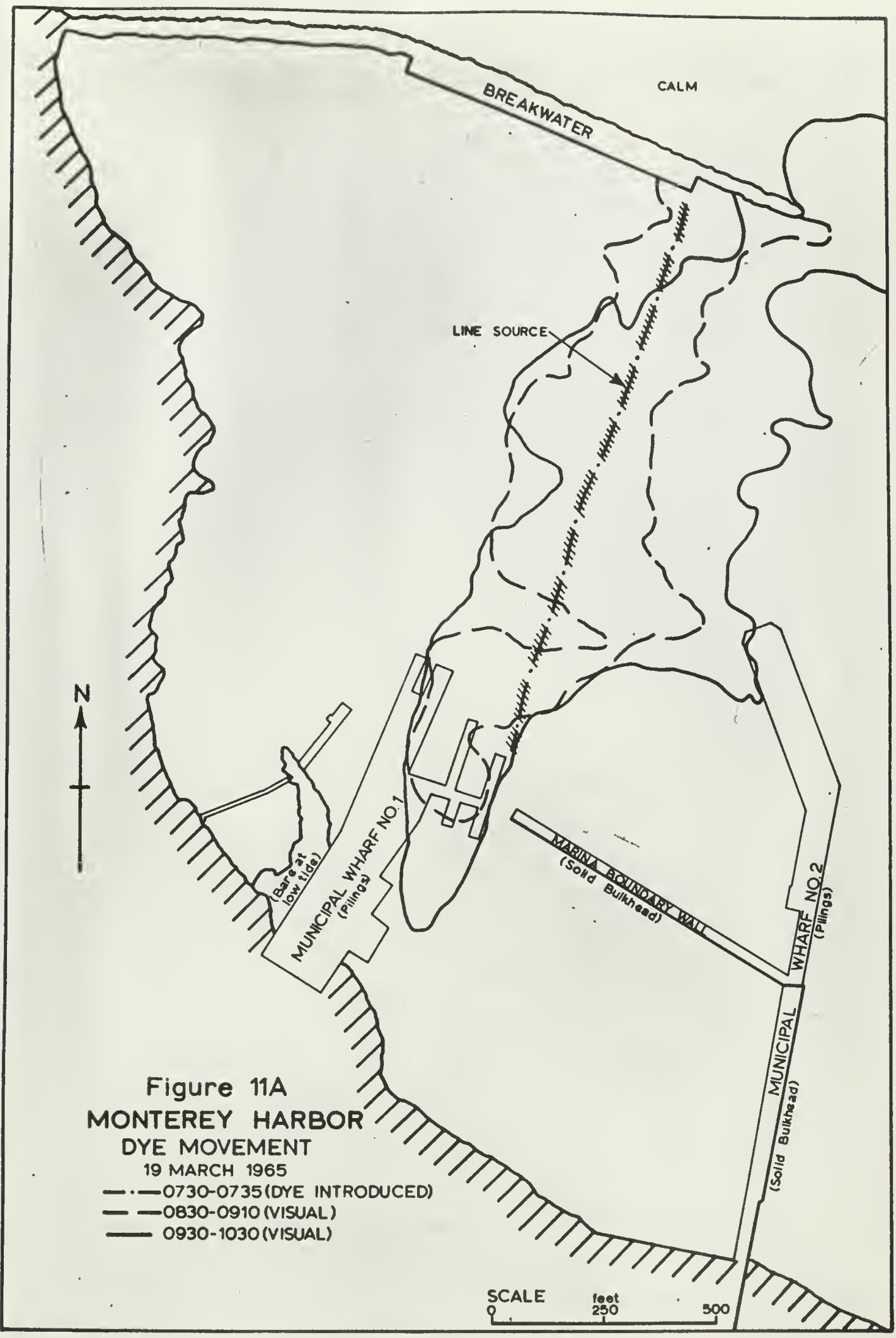





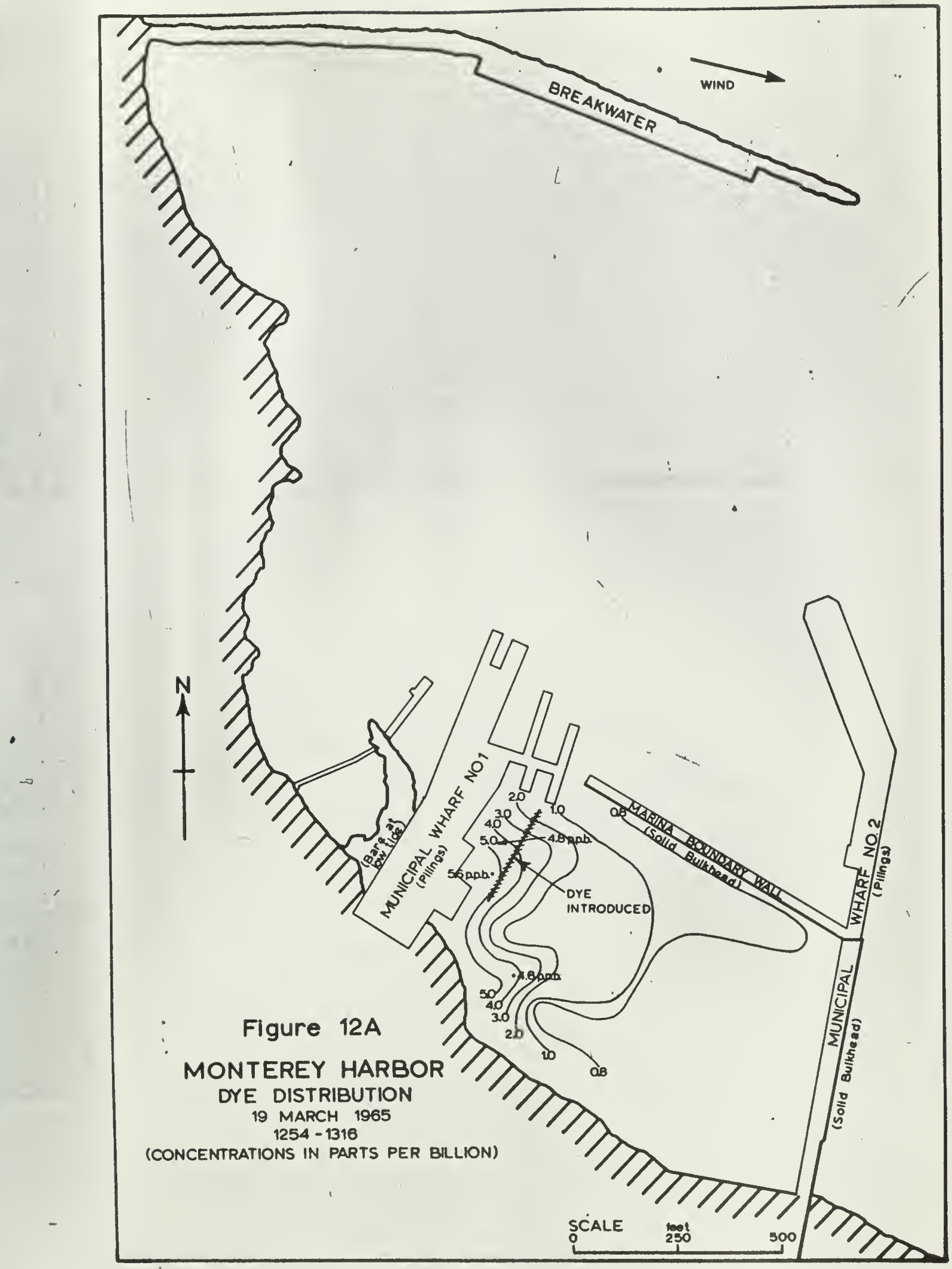





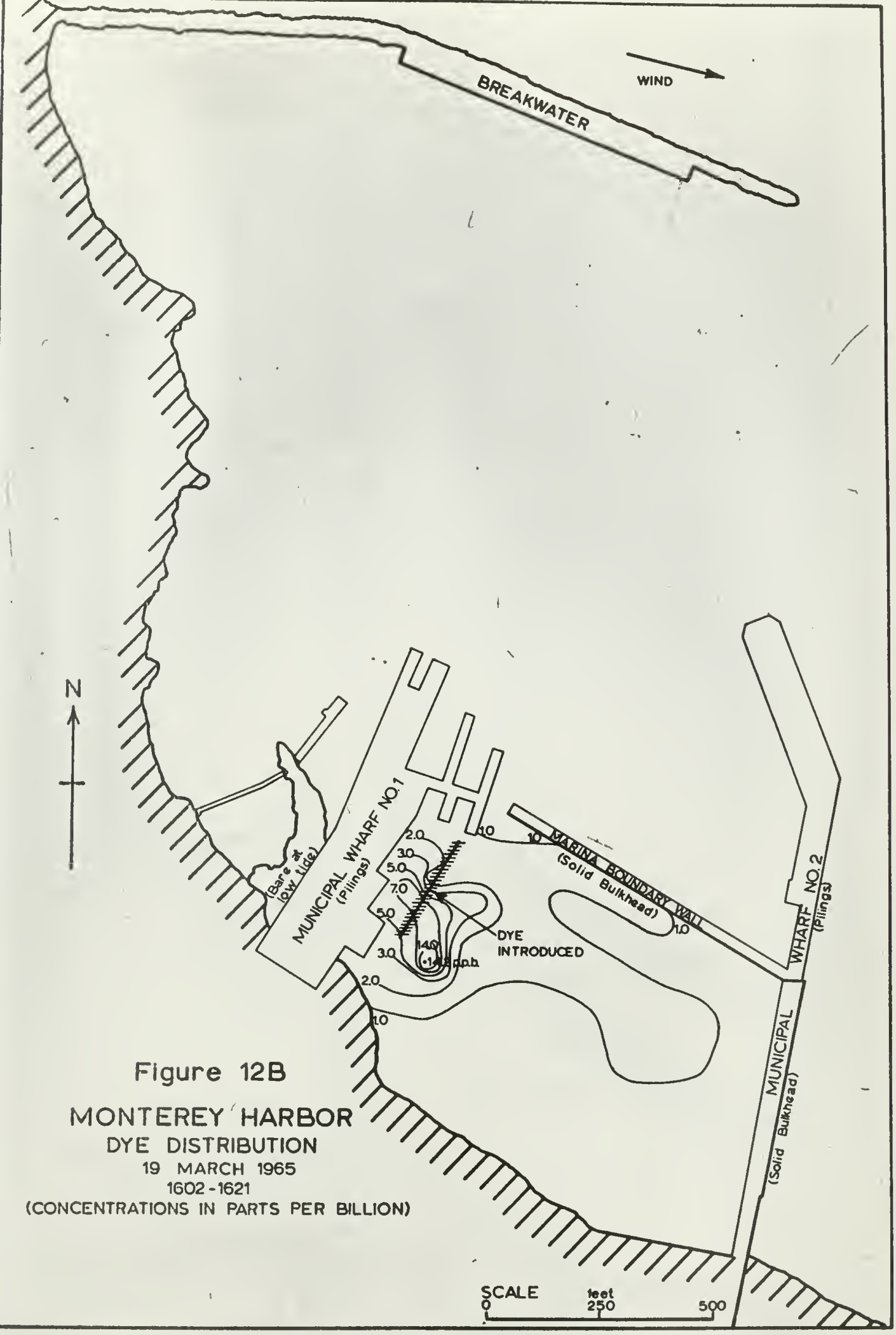




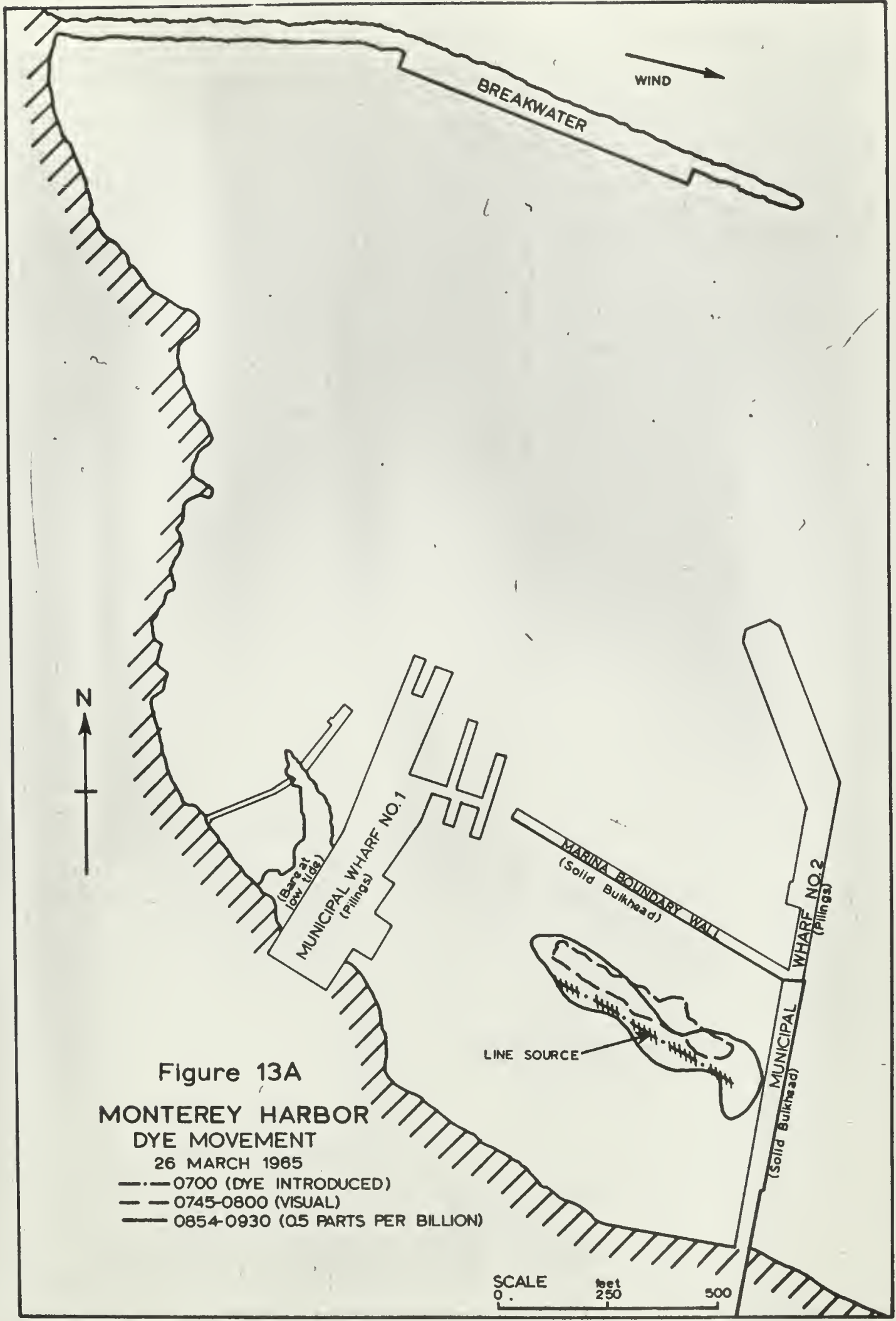





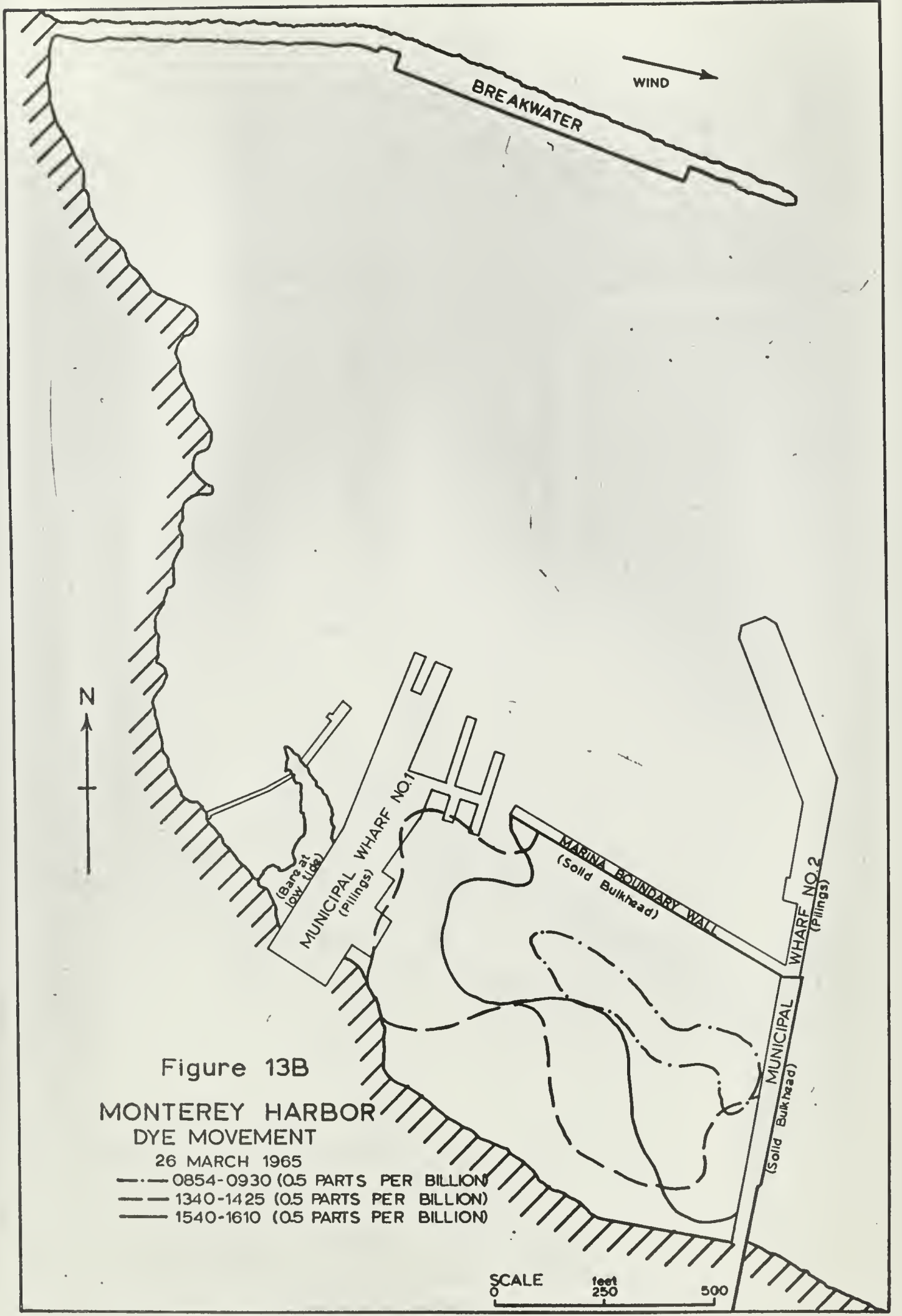





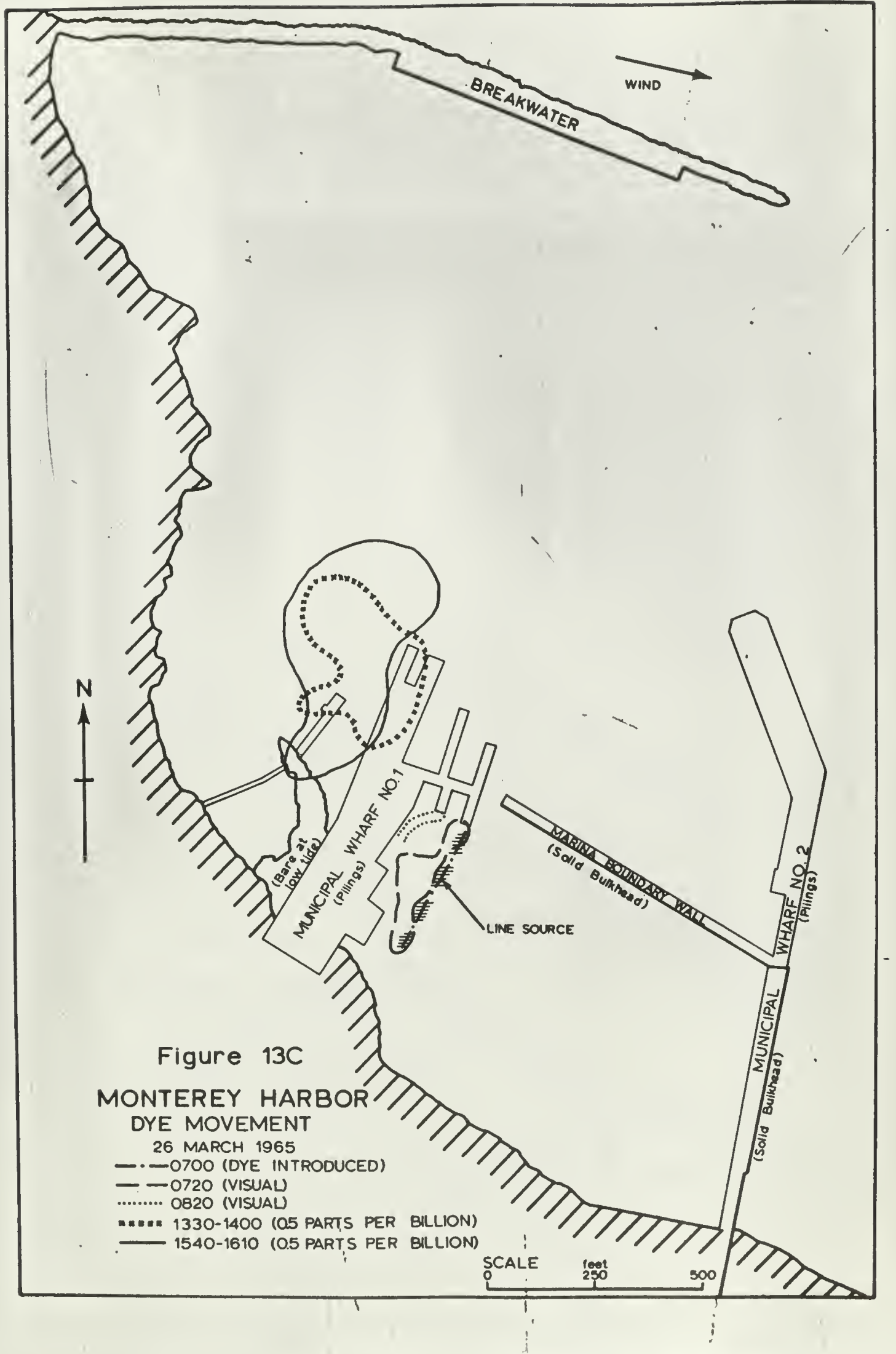





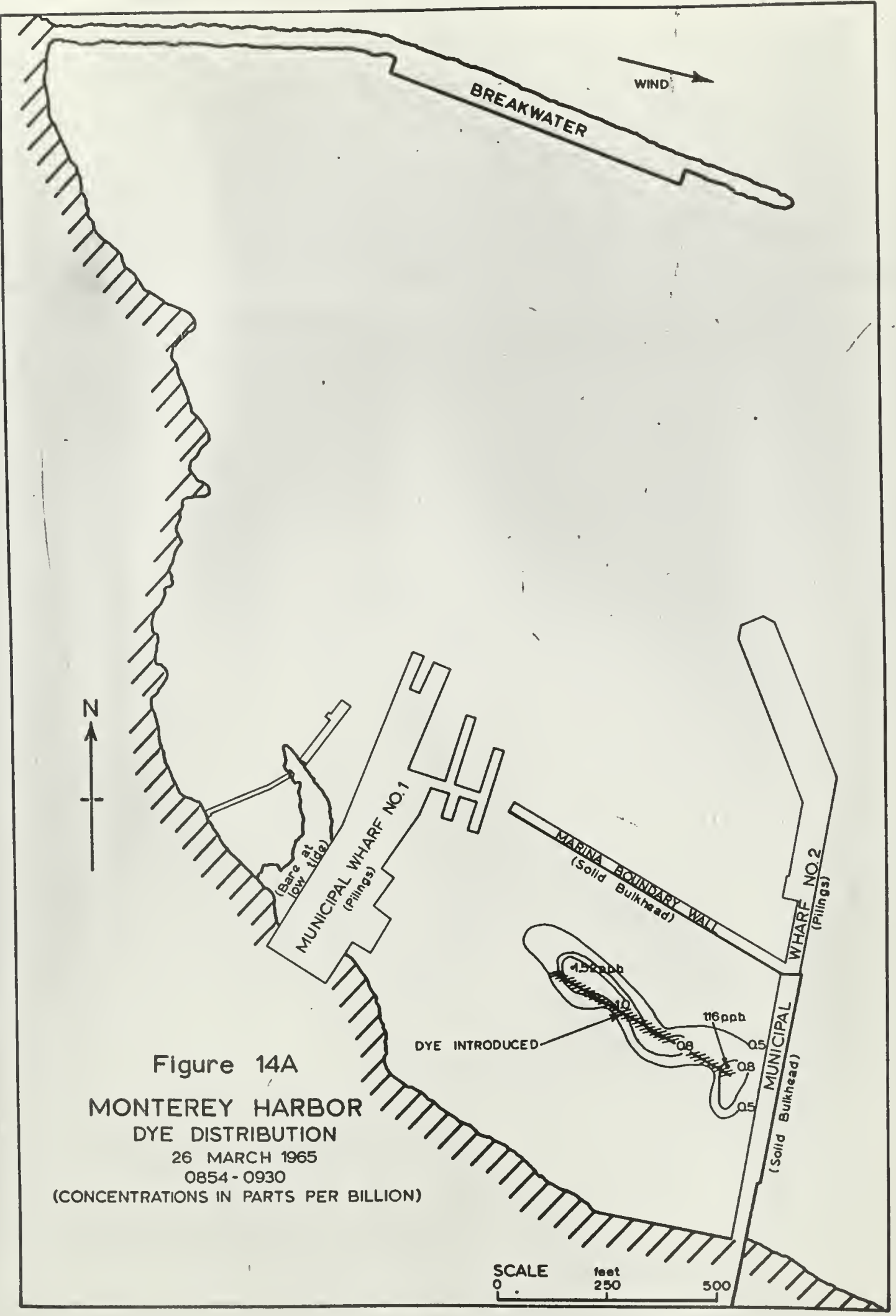






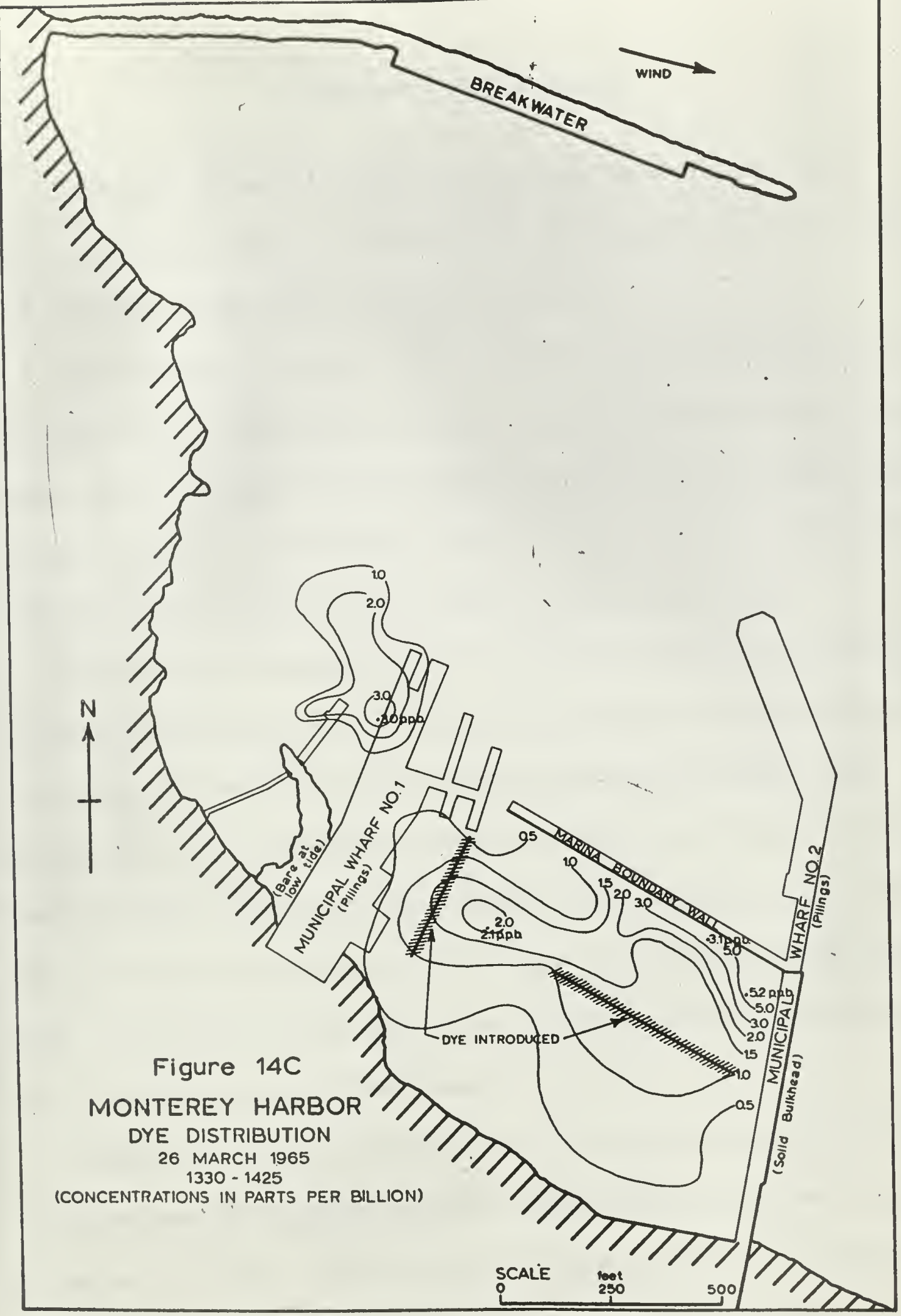





\section{COMPOSITE CIRCULATION}

Composite representations of the currents flowing during both flooding and ebbing tide, as deduced from the results of the four surveys, were prepared and are shown in Figures 15 and 16.

During flooding tide the current flow was counterclockwise in the outer harbor with relatively fast currents, up to 280 feet per hour $(0.046$ knots), observed flowing in along the breakwater, past the western shore, and out along the Marina Boundary Wall. Within the marina very small velocities were observed, with a slight counterclockwise flow.

Only Survey 4 extended over a full ebb-tide interval, and this survey was conducted in the marina. On Survey 2, however, a little additional information was collected outside the marina during the falling tide. Consequently, the flow chart for the ebbing tide is not complete. It is clear, however, that no rotation occurred within the marina during falling tide. The flow was directly out of the marina and north along the western shore. As shown by the dashed arrows, it is assumed that the flow was out of the harbor along the breakwater.

Approximate current speeds based on the movement of dye concentration centers and on dye boundary movement minus diffusion have been cited in the summaries of several of the surveys. However, because of the difference in tide ranges occurring during surveys, these cannot readily be reduced to a common reference. It seems reasonable that the maximum current speeds 
during a tide cycle can be expected to vary directly with the tide range. Hence, the arrows in these figures represent direction only, with no magnitudes implied'by their lengths.

The data on subsurface water flow was insufficient for the construction of similar circulation charts. It appeared during most of the observations that the subsurface flow reflected that at the surface, which is to be expected in view of the shallow depths in the harbor. However, the possibility of an indepenoently moving subsurface flow was indicated in the case of Surveys 3 and 4 . 



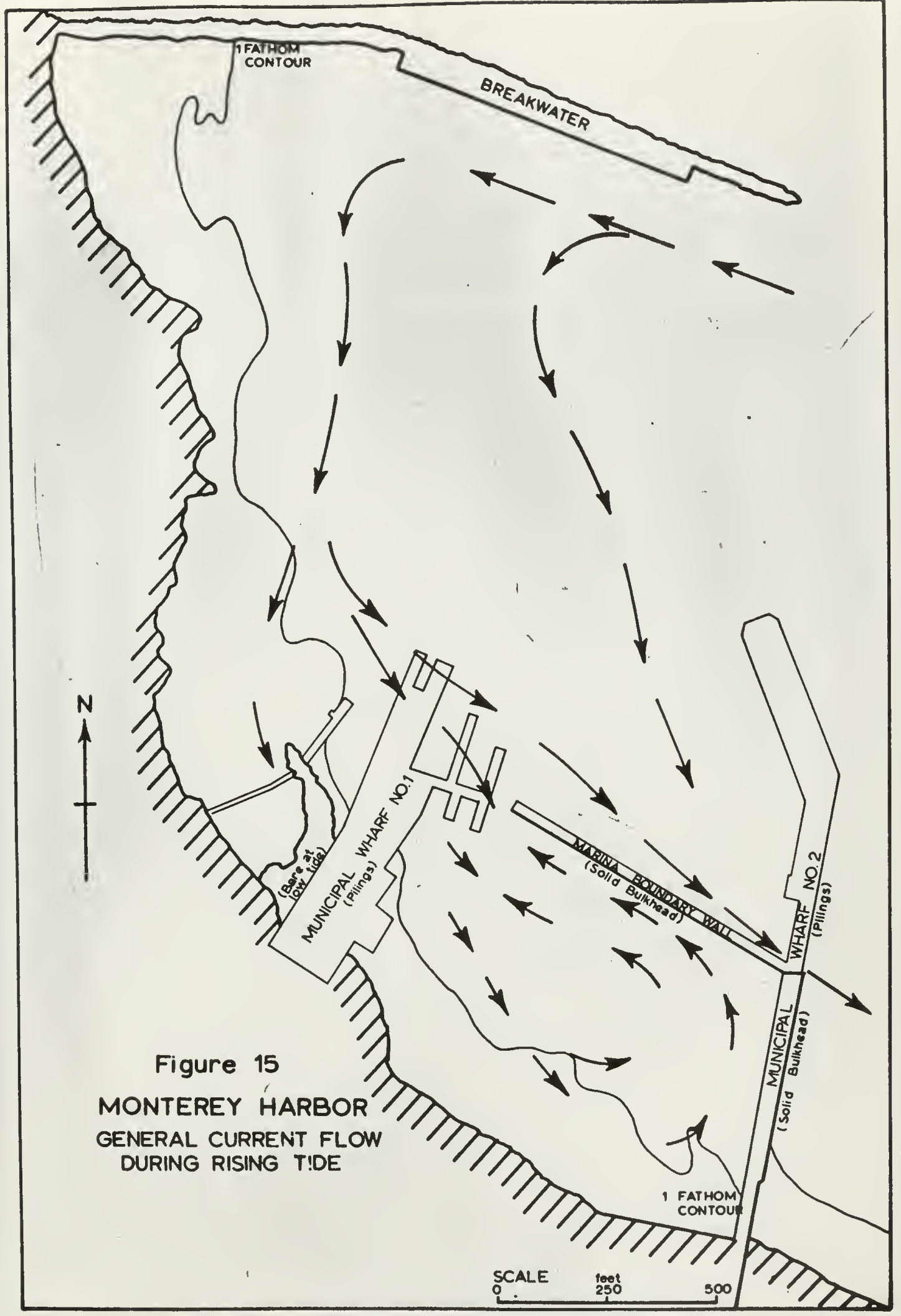





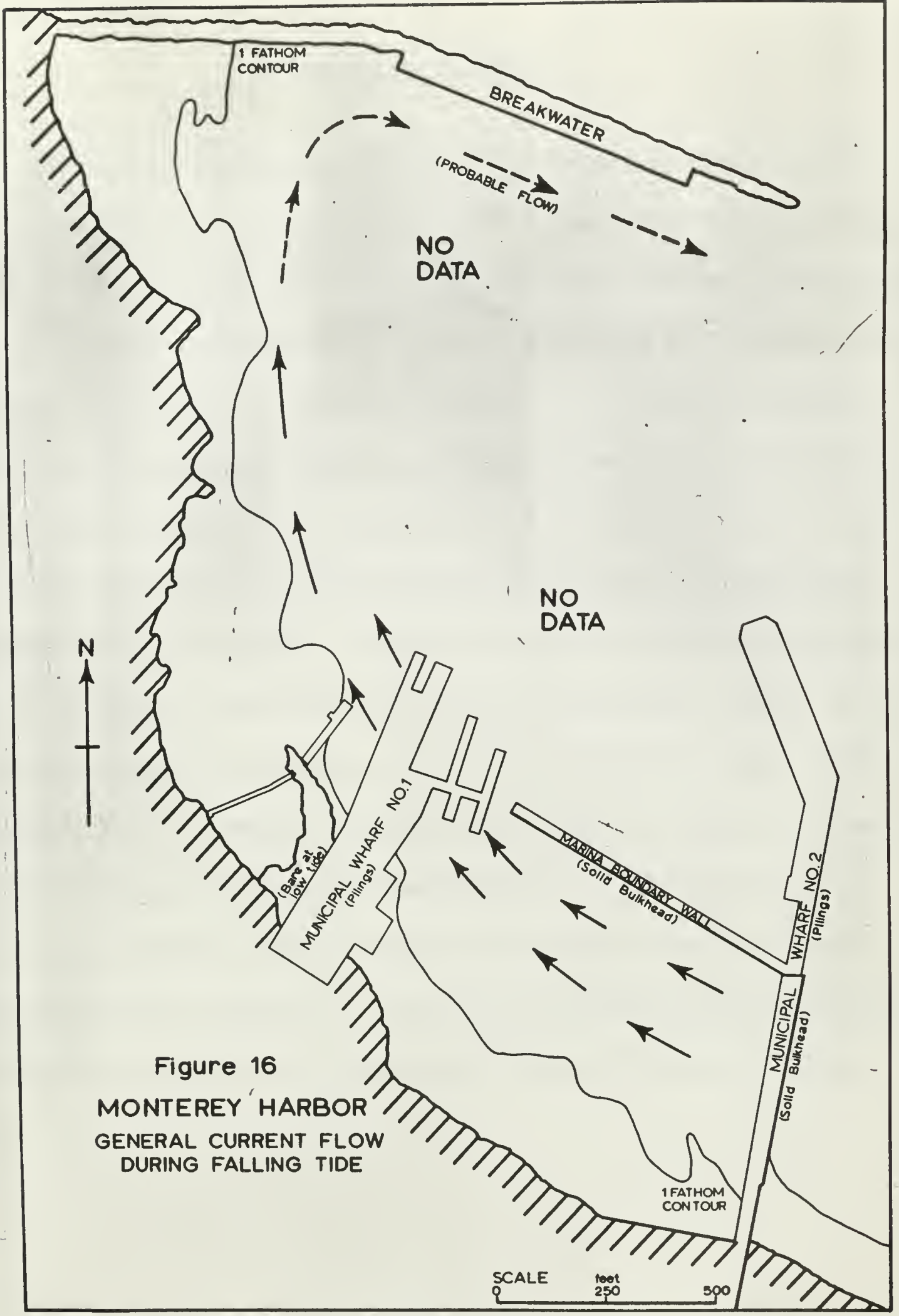





\section{ACKNOWLEDGMENTS}

The authors gratefully acknowledge the encouragement and assistance of Professor Warren C. Thompson of the U. S. Naval Postgraduate School. They also express their appreciation to: Mr. W. O. Cheney of the Pacific Gas and Electric Company for the use of a fluorometer and an electric submersible pump; Mr. D. L. Feuerstein and Dr. D. I. Jenkins of the University of California, who provided a fluorometer during the early stages of the study; and Mr.G. K. Turner and Dr. R. E. Phillips of G. K. Turner Associates for the use of a "flow-through-door" for the fluorometer and for their advice and counsel. Others to whom the writers are indebted are: Mr. L. B. Bowhay, Harbormaster of the City of Monterey, and Mr.A.D. Russell, Monterey City Engineer, for the use of the city's boats and other facilities; Mr。L.J. White, Physical Science Aide to Professor Thompson, for his assistance with the field surveys; Mr. L. J. Fisher of the U.S. Naval Oceanographic Office for advice on the use of dyes; and Mrs. D. M. Thomas for typing assistance. This study was partially supported through an Office of Naval Research Institutional Grant to Professor Thompson. 



\section{BIBLIOGRAPHY}

Dowling, G. B., and F. C. W. Olson, 1964. Diffusion in Oceans and Fresher Water. Science,v. 146, December 11: 1492.

Feuerstein, D. L. and R. E. Selleck, 1963. Tracers for Dispersion Measurements in Surface Waters. Sanitary Engineering Research Laboratory, College of Engineering and School of Public Health, University of California. SERL Report No.63-1, February 1.

Pritchard, D. W., and J. H. Carpenter, 1960. Mea surements of Turbulent Diffusion in Estuarine and Inshore Waters. Chesapeake Bay Institute. Johns Hopkins University. Association Internationale d'Hydrologie Scientifique, Bulletin No. 20, December: 37-50.

Schönfeld, J.C., and P. Groen, 1961. Mixing and Exchange Processes. International Atomic Energy Agency, Safety Series No. 5: 101-132. 






A study of water circulation in Monterey

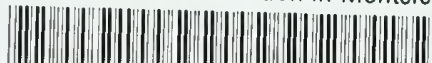

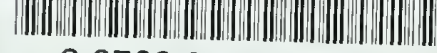

32768002072316

DUDLEY KNOX LIBRARY 